\title{
LIFE CYCLE ASSESSMENT OF DIESEL AND ELECTRIC PUBLIC TRANSPORTATION BUSES
}

by

Gregory A. Cooney

BS in Chemical Engineering, Pennsylvania State University, 2005

Submitted to the Graduate Faculty of the

Swanson School of Engineering in partial fulfillment

of the requirements for the degree of

Master of Science

University of Pittsburgh 


\title{
UNIVERSITY OF PITTSBURGH \\ SWANSON SCHOOL OF ENGINEERING
}

This thesis was presented

by

\author{
Gregory A. Cooney
}

It was defended on

June 24, 2011

and approved by

Amy E. Landis, Ph.D., Assistant Professor, Department of Civil and Environmental Engineering

Troy R. Hawkins, Ph.D., Adjunct Professor, Department of Civil and Environmental Engineering

Vikas Khanna, Ph.D., Assistant Professor, Department of Civil and Environmental Engineering

Thesis Advisor: Joe Marriott, Ph.D., Adjunct Professor, Department of Civil and Environmental Engineering 
Copyright (C) by Gregory A. Cooney 2011 


\title{
LIFE CYCLE ASSESSMENT OF DIESEL AND ELECTRIC PUBLIC TRANSPORTATION BUSES
}

\author{
Gregory A. Cooney, M.S.
}

University of Pittsburgh, 2011

In 2005, there were approximately 50,000 diesel powered public transit buses operating in the United States, consuming over 500 million gallons of fuel annually. The Clean Air Act identifies diesel powered motor vehicles, including transit buses, as significant sources of several criteria pollutants which contribute to ground level ozone formation or smog. The effects of air pollution in urban areas are often more significant due to congestion and can lead to respiratory and cardiovascular health impacts. Life cycle assessment has been utilized in the literature to compare conventional gasoline powered passenger cars with various types of electric and hybrid powered alternatives; however, no similarly detailed studies exist for mass transit buses.

LCA results from this study indicate that the use phase, consisting of diesel production/combustion for the conventional bus and electricity generation for the electric bus, dominates most impact categories; however, the effects of battery production are significant for global warming, carcinogenics, ozone depletion, and ecotoxicity. There is a clear connection between the mix of power generation technologies and the preference for the diesel or electric bus. With the existing U.S. average grid, there is a strong preference for the conventional diesel bus over the electric bus when considering global warming impacts alone. Policy makers must consider regional variations in the electricity grid prior to recommending the use of battery electric buses to reduce $\mathrm{CO}_{2}$ emissions. This study found that the electric bus was preferable in only eight states including Washington and Oregon. Improvements in battery technology reduce the life cycle impacts from the electric bus, but the electricity grid makeup is the dominant variable. 
TABLE OF CONTENTS

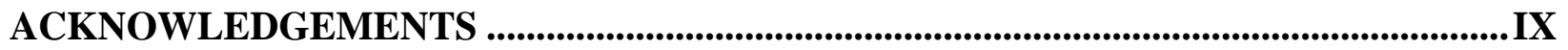

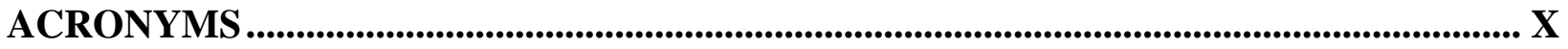

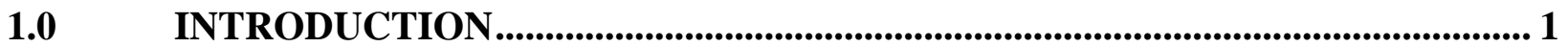

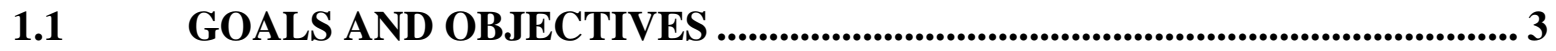

1.2 LIFE CYCLE ASSESSMENT............................................................................. 4

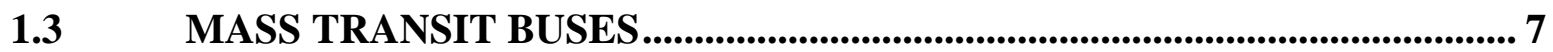

1.4 BATTERY ELECTRIC VEHICLES .................................................................. 10

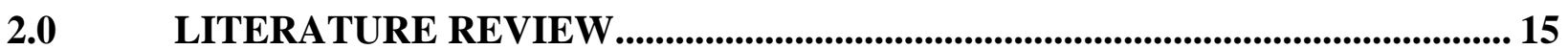

2.1 SUMMARY OF MASS TRANSIT AND EV STUDIES .............................. 15

2.2 COMPARISON OF LIFE CYCLE RESUTLS FROM LITERATURE...... 19

2.2.1 ICEB and EB LCA Study Results from Literature....................................... 19

2.2.2 EV Battery LCA Studies from Literature......................................................... 22

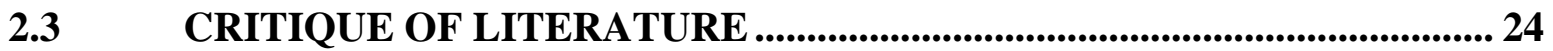

3.0 LIFE CYCLE ASSESSMENT OF TRANSIT BUSES ............................................ 30

INTRODUCTION

3.1.1 Significance of environmental impacts of buses ............................................. 30

3.2 BACKGROUND AND LITERATURE REVIEW ........................................... 32

3.2.1 Mass Transit Studies ............................................................................................... 32 
3.2.2 Li-ion LCA studies form literature ................................................... 33

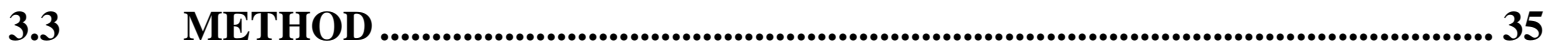

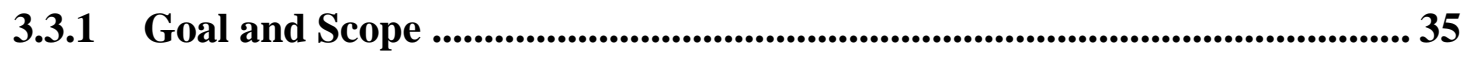

3.3.2 System Boundary Selection................................................................................ 36

3.3.3 System Processes and Data Sources.................................................... 38

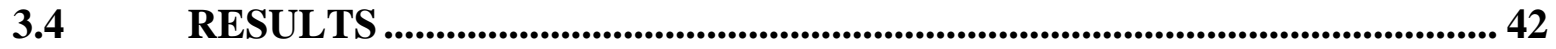

SENSITIVITY ANALYSIS OF KEY PARAMETERS ................................. 47

3.5.1 Electricity Grid Impact............................................................................. 47

3.5.2 Li-ion Battery Technology Impacts ................................................... 50

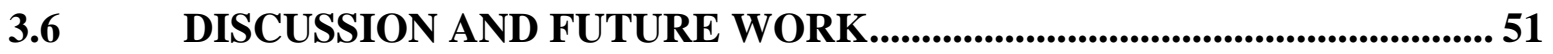

4.0 CONCLUSIONS AND FUTURE WORK ........................................................ 52

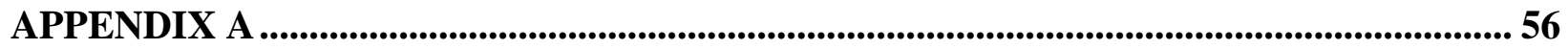

APPENDIX B

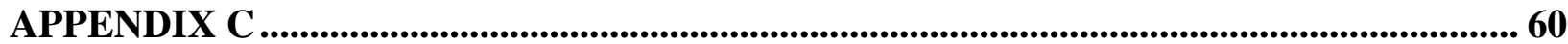

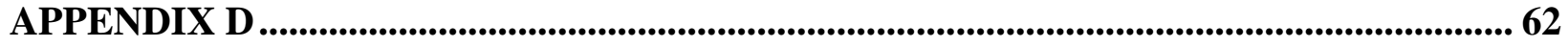

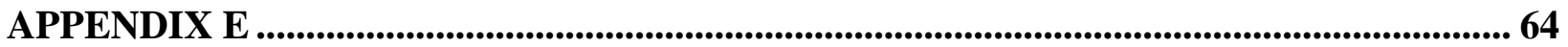

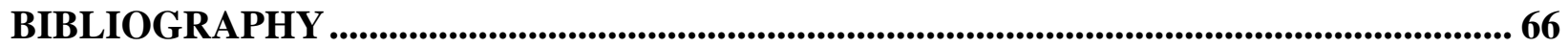




\section{LIST OF TABLES}

Table 1-1. Estimated emissions and fuel use for the U.S. fleet of transit buses in 2003 (Wayne \&

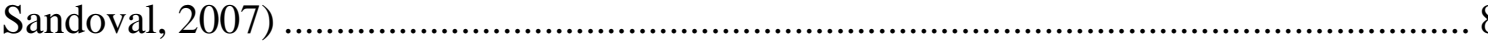

Table 1-2. Battery electric buses in operation as of July 2005 (Callaghan \& Lynch, 2005)........ 10

Table 1-3. Comparisons of Battery Technologies (Eudy \& Gifford, 2003) ............................... 12

Table 1-4. Comparisons of Transit Bus Technology Capital Cost (Callaghan \& Lynch, 2005; Eudy \& Gifford, 2003)...................................................................................... 13

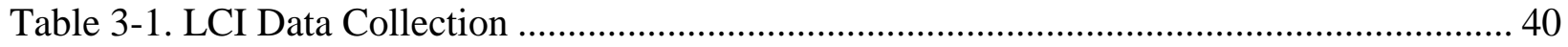

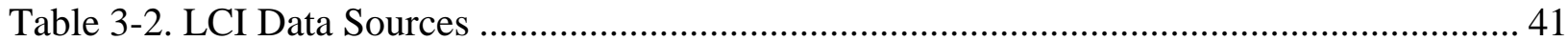




\section{LIST OF FIGURES}

Figure 1-1. U.S. Energy-Related Carbon Dioxide Emissions by End-Use Sector in million metric

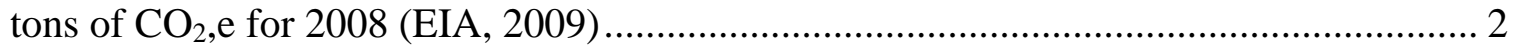

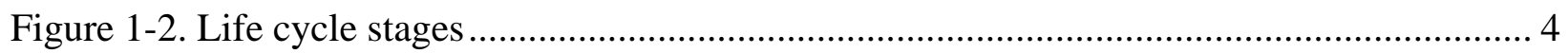

Figure 1-3. The four phases of Life Cycle Assessment ..................................................... 5

Figure 1-4. Percentage of transportation vehicles and transportation related air emissions for

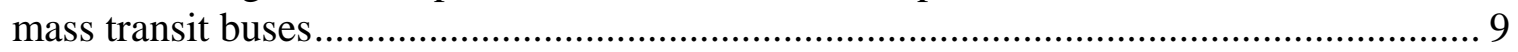

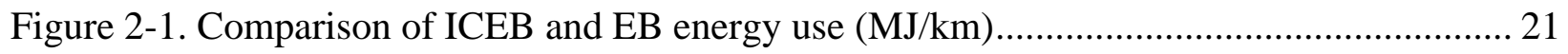

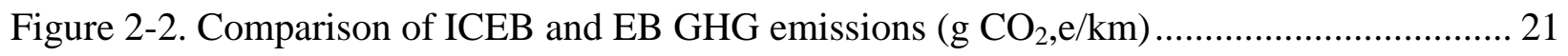

Figure 3-1. LCA study process flow chart and system boundary ....................................... 38

Figure 3-2. Life Cycle Assessment Results for Base Case .................................................. 44

Figure 3-3. Use phase emissions of EPA criteria pollutants per vehicle-kilometer; includes electricity generation and battery production for EB and diesel production and

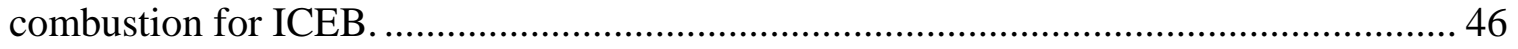

Figure 3-4. Production and Use Phase Life Cycle Assessment Global Warming Impacts as a Function of the Carbon Intensity of the Electricity Grid ............................................ 48

Figure 3-5. State-by-State Preference for EB or ICEB Accounting for Electric Grid Differences and Measured as EB Fraction of ICEB Lifetime $\mathrm{CO}_{2}$ Emissions.................................. 50 


\section{ACKNOWLEDGEMENTS}

I would like to thank my research advisors Joe Marriott and Troy Hawkins for their support and invaluable advice during the course of my graduate studies at Pitt. I would also like to thank the other SGD faculty members: Dr. Melissa Bilec, Dr. Amy Landis, and Dr. Vikas Khanna. My learning experience at Pitt extended far beyond the classroom and for that I would like to thank my fellow graduate students in the SGD program. Finally, and most importantly, I would like to thank my wife, Monica Cooney.

This work was supported in part by the National Science Foundation under NSF Award 0967353. 


\title{
ACRONYMS
}

\author{
ANL - Argonne National Laboratory \\ APTA - American Public Transportation Association \\ BEV - Battery electric vehicle \\ CCS - Carbon capture and sequestration \\ CED - Cumulative energy demand \\ CNG - Compressed natural gas \\ CO - Carbon Monoxide \\ $\mathrm{CO}_{2}$ - Carbon Dioxide \\ $\mathrm{CO}_{2} \mathrm{e}-$ Carbon Dioxide equivalent \\ DOE - Department of Energy \\ DOT - Department of Transportation \\ EB - Electric bus \\ EIA - Energy Information Administration \\ EIO-LCA - Economic input-output life cycle assessment \\ EOL - End of life \\ EPA - Environmental Protection Agency \\ EV - Electric Vehicle
}


FTA - Federal Transit Administration

GHG - Greenhouse Gas

GREET - Greenhouse gases, Regulated Emissions, and Energy use in Transportation

GWP - Global warming potential

HEV - Hybrid electric vehicle

ICE - Internal combustion engine

ICEB - Internal combustion engine bus

ICEV - Internal combustion engine vehicle

ISO - International Organization for Standardization

LCA - Life cycle assessment

LCI - Life cycle inventory analysis

LCIA - Life cycle impact assessment

Li-ion - Lithium ion

$\mathrm{LiFePO}_{4}$ - Lithium Iron Phosphate

$\mathrm{LiMnO}_{2}$ - Lithium Manganese Oxide

LiNiCoMn - Lithium Nickel-Cobalt-Manganese

LNG - Liquefied natural gas

NAICS - North American Industry Classification System

Ni-MH - Nickel metal hydride

NMHC - Non-methane hydrocarbons

$\mathrm{NO}_{\mathrm{x}}-$ Nitrogen oxides

NREL - National Renewable Energy Laboratory

ODP - Ozone depletion potential 
PAAC - Port Authority of Allegheny County

PHEB - Plug-in hybrid electric bus

PHEV - Plug-in hybrid electric vehicle

PM - Particulate matter

PTW - Pump-to-wheels

SETAC - Society of Environmental Toxicology and Chemistry

$\mathrm{SO}_{2}$ - Sulfur dioxide

$\mathrm{SO}_{\mathrm{x}}-$ Sulfur oxides

UNEP - United Nations Environment Programme

VOC - Volatile organic compound

WTP - Well-to-pump

WTW - Well-to-wheels 


\subsection{INTRODUCTION}

Climate change is a significant problem that has resulted from anthropogenic greenhouse gas (GHG) emissions, namely carbon dioxide. As shown in Figure 1-1, one-third of anthropogenic $\mathrm{CO}_{2}$ emissions in the United States are from the transportation sector (EIA, 2009). Even though buses only represent $1 \%$ of all of the transportation vehicles in the United States, they account for $44 \%$ of the 50 billion public transit passenger miles annually and often operate in dense urban centers (American Public Transportation Association, 2010; Eudy \& Gifford, 2003). In addition to the GHG emissions from mass transit buses, there are concerns with regard to other hazardous air pollutants. The Clean Air Act (1990) identifies diesel powered motor vehicles, including transit buses, as significant sources of several criteria pollutants which contribute to ground level ozone formation or smog. The effects of air pollution in urban areas are often more significant due to congestion and can lead to respiratory and cardiovascular health impacts (Koren, 1995). As a result, many transit agencies have considered transitioning to other types of fuels and bus technologies that reduce air pollution emissions compared to conventional diesel buses. 


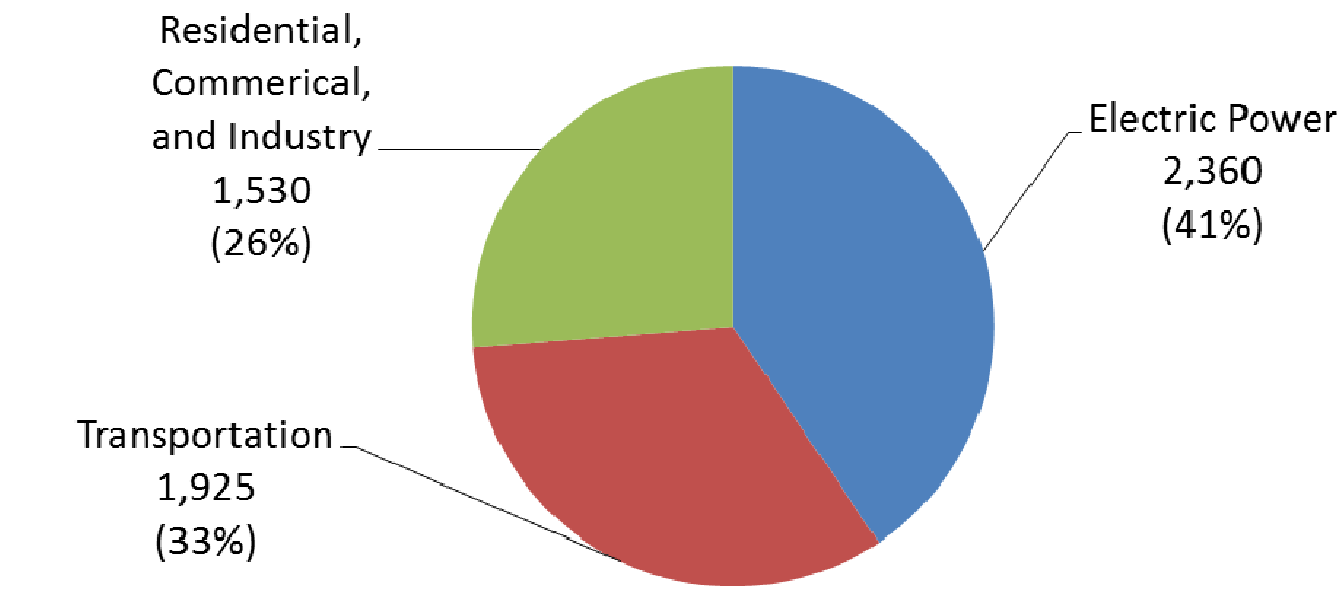

Note: Mass Transit Buses Account for $0.3 \%$ of Transportation Sector

Figure 1-1. U.S. Energy-Related Carbon Dioxide Emissions by End-Use Sector in million metric tons of $\mathrm{CO}_{2}$,e for 2008 (EIA, 2009)

This paper and life cycle assessment (LCA) focus specifically on a life cycle comparison of the environmental impacts from conventional internal combustion engine buses (ICEBs) with those associated with battery electric buses (EBs). The pollution impacts of shifting the predominant mass transit bus platform from ICEBs to EBs are unknown and are the main motivation for this study. There is documented research comparing conventional and batterypowered options for automobiles (Majeau-Bettez, Hawkins, \& Stromman, 2010; Notter et al., 2011; Samaras \& Meisterling, 2008); however, similar research focusing on battery electric models for larger service vehicles, like mass transit buses, is lacking in depth. In addition to shifting emissions from distributed tailpipes to power plant point sources, there are battery production impacts that must also be considered when examining a proposed conversion of bus technology. 


\subsection{GOALS AND OBJECTIVES}

The goal of this research is to conduct a comparative environmental life cycle assessment of a conventional diesel powered mass transit bus (ICEB) and a theoretical battery electric mass transit bus (EB).

The specific objectives are as follows:

- Combine process LCA with economic input-output (EIO)-LCA to improve the understanding of the environmental impacts associated with the manufacturing and operation of both vehicle types.

- Examine the degree of environmental impact attributed to the production of the lithium-ion (Li-ion) battery for the EB and the importance of battery replacements during the life cycle of the vehicle.

- Evaluate the importance of the mix of electricity generation technologies in terms of the preference for bus platform in terms of the minimization of GHG emissions.

- Determine a state-by-state preference for bus platform in terms of the minimization of GHG emissions.

- Perform sensitivity studies to examine the importance of Li-ion battery cycle life, energy density, and electric drive efficiency to the comparison of the two vehicles. 


\subsection{LIFE CYCLE ASSESSMENT}

Life cycle assessment (LCA) is a tool that can be used to track the potential environmental impacts of a product or process from cradle to grave. As shown in Figure 1-2, an LCA typically consists of four generalized stages to track the life cycle of a product or process: (1) raw material extraction (2) production or manufacturing (3) use (4) disposal/recycling or end of life (EOL) (UNEP, 2005). Transportation impacts are implicit during and between each of the life cycle processes.

\section{Raw Material \\ Extraction}

\section{Manufacturing}
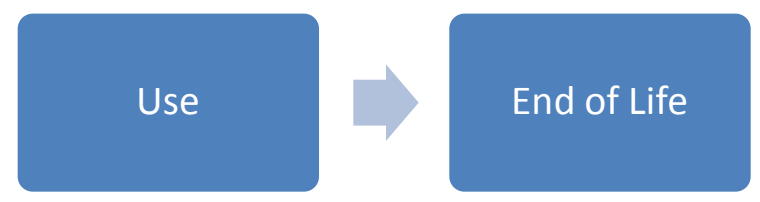

Figure 1-2. Life cycle stages

Several organizations, including the International Organization for Standardization (ISO), the Society of Environmental Toxicology and Chemistry (SETAC), and the U.S. Environmental Protection Agency (EPA), have taken a role in developing standards for performing LCAs (Hendrickson, Lave, \& Matthews, 2006). The most frequently sited standards for international LCAs are ISO 14040 and 14044, which prescribe the following four steps for conducting the LCA study as shown in Figure 1-3: (1) goal and scope definition (2) life cycle inventory analysis (LCI) (3) life cycle impact assessment (LCIA) (4) interpretation and improvement analysis (Bauman \& Tillman, 2004; ISO, 2006). While the first step appears to be straightforward, it is often the source of most contention in comparing and conducting LCA studies and can lead to significant differences in the results and conclusions of similar studies. 


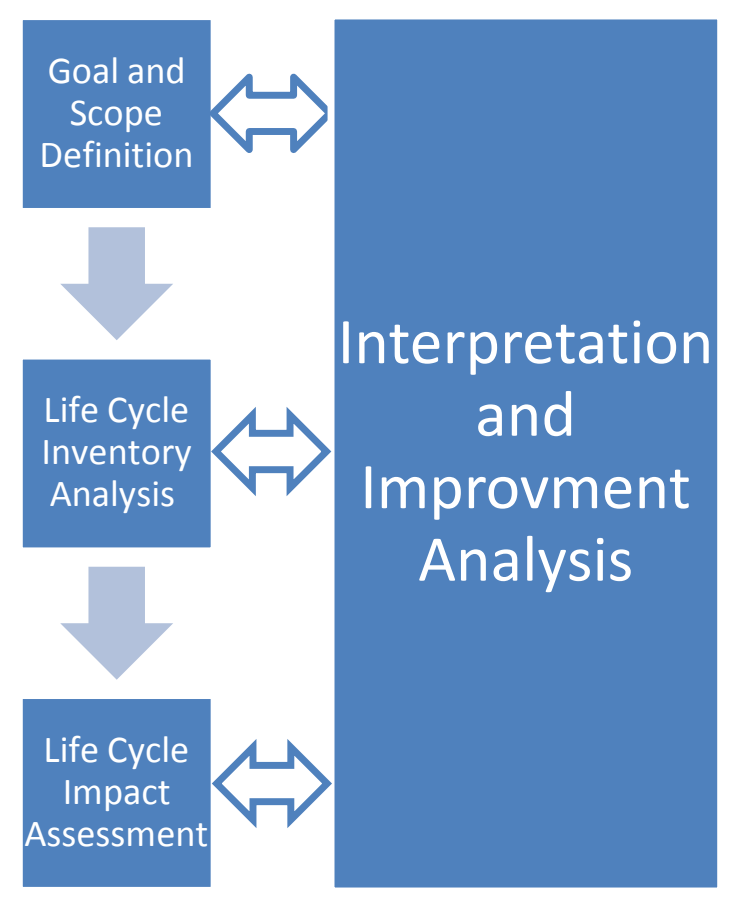

Figure 1-3. The four phases of Life Cycle Assessment

To adequately assess a product or process, it is important to include both the direct impact, as well as the indirect impacts, including the supply chain, which can add considerably to the overall emissions that are attributed to a system. Once the scope of a study is determined, the system boundary is set and the individual unit processes are determined. Next, emissions are collected and aggregated in the LCI stage. Information regarding the individual processes required for the overall LCA can come from various sources including peer-reviewed journal articles, government reports, and measured data provided by industry. There are several databases that compile LCI data for various processes and products available commercially. This study utilizes the USLCI and EcoInvent databases for calculating environmental impacts (Hischier et al., 2010; NREL, 2004). Some studies end at the LCI stage; however, some continue on to the LCIA, where the emissions are correlated to impacts via various tools and methods including the following: global warming potential (GWP), ozone depletion potential 
(ODP), respiratory inorganics (PM), carcinogens, non-carcinogens, respiratory organics, aquatic ecotoxicity, aquatic acidification, aquatic eutrophication, terrestrial ecotoxicity, and terrestrial acidification (Jolliet et al., 2003). This study utilizes IMPACT 2002 to categorize the environmental impacts from the LCI data.

There are three main types of LCA methods: process LCA, economic input-output (EIO) LCA, and hybrid LCA (Weisser, 2007). Process LCA is used to examine all of the specific subprocesses involved with a product or process and as a result, it is the most detailed type of LCA. However, it is data and time intensive, and there are often challenges in retrieving process data that is not widely available, especially in cases where the information is proprietary (Hendrickson, et al., 2006). EIO-LCA simplifies the process of conducting a LCA by taking a more aggregate view of all of the sectors of the U.S. economy that are involved in product or process. EIO-LCA utilizes two major simplifications that enable the user to conduct an LCA more quickly and without significant cost: (1) the model assumes that an increase in output requires an equal increase in the inputs, meaning that the average production conditions as opposed to the marginal impacts associated with changes in production (2) all production and services are aggregated to approximately 500 sectors of the U.S. economy. An advantage of EIO-LCA is that it is able to capture the supply chain impacts that are nearly impossible to track with a process LCA. One of the limitations of the EIO-LCA method is that it is often difficult to find complete data for the environmental effects related to the economic activity modeled by the tool (Hendrickson, et al., 2006). As a rule-of-thumb, a product evaluated with the EIO-LCA method typically results in emissions that are 30\% higher than those resulting from a conventional process LCA (Weisser, 2007). Hybrid LCA combines attributes from both process and EIO-LCA. 
The ISO guidelines for determining which inputs can be cutoff from a study are particularly ambiguous and inherently requires some subjective decision-making on the part of the LCA practitioner (Suh et al., 2003). As a result of these issues, methods have been developed to incorporate the resolution of the process LCA with the all-encompassing approach of EIO-LCA. Hybrid LCA can be used to incorporate both physical and monetary units into the study which allows for the inclusion of sector and process data. Although the hybrid framework provides a more complete look into a process or product, it comes at the expense of additional uncertainty inherent with both the monetary and physical quantities (Hawkins, Hendrickson, Higgins, Matthews, \& Suh, 2006). Similar to the process LCA, hybrid LCA is also highly dependent on the availability of quality data for the process that is being investigated. This study utilizes both process-based and EIO-LCA methods in order to determine the environmental impacts associated with both bus platforms. Process-based methods were used to evaluate the diesel and electricity production and consumption unit processes along with the production of the Li-ion battery for the EB. EIO-LCA was used to model the production of the bus frame and supporting components, along with maintenance activities and the production of the charging infrastructure for the EB.

\subsection{MASS TRANSIT BUSES}

Wayne and Sandoval (2007) completed a study for the U.S. Department of Transportation (DOT) division known as the Federal Transit Administration (FTA) which examined the prospective environmental benefits associated with alternative fuels and technologies specifically for mass transit buses. In 2005, there were approximately 50,000 diesel powered public transit 
buses operating in the United States, consuming over 500 million gallons of fuel annually. Based on transit authority surveys conducted in 2005, mass transit buses typically average 2.8 to 3.4 miles per gallon of diesel fuel. As a result of the combustion process, transit buses account for 5.9 million metric tons of carbon dioxide $\left(\mathrm{CO}_{2}\right)$, 59,000 metric tons of nitrogen oxides $\left(\mathrm{NO}_{\mathrm{x}}\right)$, 14,000 metric tons of carbon monoxide (CO), 2,400 metric tons of non-methane hydrocarbons (NMHC) and 1,300 metric tons of PM emitted to the atmosphere on an annual basis. Table 1-1 provides emissions information for various bus platforms that are operating as part of the U.S. transit fleet.

Table 1-1. Estimated emissions and fuel use for the U.S. fleet of transit buses in 2003 (Wayne \& Sandoval, 2007)

\begin{tabular}{|l|c|c|c|c|c|c|c|c|}
\hline Fuel Type & $\begin{array}{c}\text { Number } \\
\text { of Buses }\end{array}$ & $\mathbf{C O}$ & $\mathbf{N M H C}$ & $\mathbf{C H}_{\mathbf{4}}$ & $\mathbf{N O x}$ & $\mathbf{P M}$ & $\mathbf{C O}_{\mathbf{2}}$ & Fuel Use \\
\hline & & $\begin{array}{c}\text { metric } \\
\text { tons }\end{array}$ & $\begin{array}{c}\text { metric } \\
\text { tons }\end{array}$ & $\begin{array}{c}\text { metric } \\
\text { tons }\end{array}$ & $\begin{array}{c}\text { metric } \\
\text { tons }\end{array}$ & $\begin{array}{c}\text { metric } \\
\text { tons }\end{array}$ & $\begin{array}{c}\text { metric } \\
\text { tons }\end{array}$ & $\begin{array}{c}\text { thousands } \\
\text { of gallons }\end{array}$ \\
\hline Diesel & 50,000 & 14,400 & 2,400 & - & 60,000 & 1,350 & $5,900,000$ & 590,000 \\
\hline CNG/LNG & 7,600 & 1,100 & 280 & 5,300 & 5,700 & 6 & 723,000 & 100,000 \\
\hline $\begin{array}{l}\text { Diesel } \\
\text { Hybrid }\end{array}$ & 490 & 5 & 0.6 & - & 200 & 0.5 & 32,500 & 3,300 \\
\hline \hline Total & 58,000 & 15,500 & 2,700 & 5,300 & 66,000 & 1,350 & $6,660,000$ & 693,000 \\
\hline
\end{tabular}

While this study focuses on applications of mass transit buses across the entire U.S., it is important to consider the regional context. Locally, the Port Authority of Allegheny County (PAAC) operates 861 buses serving almost 200,000 passengers on a daily basis (PAAC, 2010). In 2009, PAAC buses operated for more than 27 million miles (43 million kilometers) (2010). All of the operations in PAAC, including buses an paratransit services, consumed 11.8 million gallons (44.7 million liters) of fuel in the 2005-06 fiscal year (PENNDOT, 2007).

Even though buses only represent $1 \%$ of all of the transportation vehicles in the United States, they account for $44 \%$ of the 50 billion public transit passenger miles annually and often 
operate in dense urban centers (American Public Transportation Association, 2010; Eudy \& Gifford, 2003). The Clean Air Act (1990) identifies diesel powered motor vehicles, including transit buses, as significant sources of several criteria pollutants which contribute to ground level ozone formation or smog. The effects of air pollution in urban areas are often more significant due to traffic congestion, high population density, and exposure rates which can lead to respiratory and cardiovascular health impacts. As shown in Figure 1-4, mass transit buses makeup only $0.02 \%$ of all vehicles in the U.S., but contribute to air emissions disproportionately when compared to the rest of the vehicle fleet (DOT, 2010; EPA, 2009).

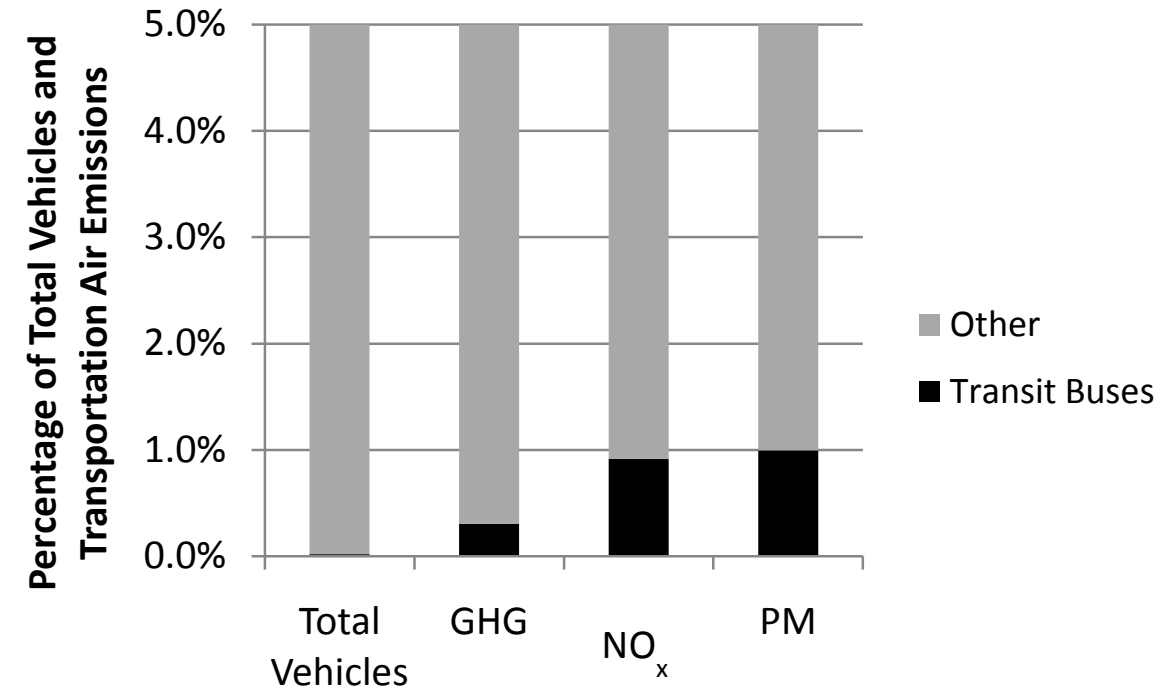

Figure 1-4. Percentage of transportation vehicles and transportation related air emissions for mass transit buses

As a result, many transit agencies have considered migrating to other types of fuels and bus technologies that result in less air pollution emissions. According to the American Public Transportation Association (2010), in 2009, 30\% of the buses in the United States were using some type of alternative fuel technology (diesel hybrid, biodiesel, compressed natural gas 
(CNG), liquefied natural gas (LNG), propane, battery electric. All of these different fuel types and technologies have advantages and disadvantages.

Electric-powered buses (EBs) have been around in the United States since the 1800s, mostly trolley-style vehicles powered by an overhead catenary line (Callaghan \& Lynch, 2005). Battery-powered buses are a relatively new development and have only been commercially available since the late 1990s. From this point forward, when the acronym EB is used, it is referring to a battery-powered electric bus. The most significant technological obstacle that EBs must overcome before they are commercially viable and widely used is the limitations of battery technology. As shown in Table 1-2, there were only 90-120 EBs operating in the United States in 2005, with the majority of these operating as 22-foot shuttle buses in niche markets with limited routes (Callaghan \& Lynch, 2005).

Table 1-2. Battery electric buses in operation as of July 2005 (Callaghan \& Lynch, 2005)

\begin{tabular}{|l|c|c|c|}
\hline Site & Number & Size (ft) & Manufacturer \\
\hline Anaheim, CA & 10 & 22 & Ebus \\
\hline Atlanta, GA (Emory Univ.) & 5 & 22 & Ebus \\
\hline Chattanooga, TN & 12 & 22 & AVS \\
\hline Colorado Springs, CO & 5 & 22 & Ebus \\
\hline Hampton, VA & 8 & 22 & AVS \\
\hline Los Angeles, CA & 18 & 22 & Ebus \\
\hline Miami, FL & 10 & 22 & AVE \\
\hline Mobile, AL & 4 & 22 & Ebus \\
\hline New Haven, CT & 4 & 22 & Ebus \\
\hline Santa Barbara, CA & 20 & 22 & Various \\
\hline
\end{tabular}

\subsection{BATTERY ELECTRIC VEHICLES}

There are three types of electric vehicles (EVs): hybrid electric vehicles (HEVs), plug-in hybrid electric vehicles (PHEVs), and battery electric vehicles (BEVs). Both HEVs and PHEVs 
incorporate electric drive with a conventional internal combustion engine (ICE). The difference between the two technologies is that the PHEV requires recharging, as the title implies, and it can be driven on electric power exclusively so long as there is a required minimum charge left in the battery. BEVs do not have an ICE installed onboard. They rely solely on electric power for propulsion. The drivetrain for a BEV consists of three major component systems: (1) the electric motor, (2) battery pack (3) control system, which in some cases includes a transmission and/or a battery temperature control system (Callaghan \& Lynch, 2005). As a result of their design, BEVs are able to achieve the highest torque at low speeds, which makes them particularly attractive for mass transit bus applications because of the frequent stops for passenger drop-off and pickup (Callaghan \& Lynch, 2005).

Limitations in battery technology are the biggest impediment to widespread adoption of EBs. There are a number of different battery technologies, including lead-acid, nickel-metalhydride (Ni-MH), and lithium-ion (Li-ion). There are a number of Li-ion battery variants based on the type of materials utilized for the electrodes, for example lithium nickel cobalt manganese (LiNiCoMn), lithium manganese oxide $\left(\mathrm{LiMnO}_{2}\right)$, and lithium iron phosphate $\left(\mathrm{LiFePO}_{4}\right)$. The most important characteristics of a battery are the specific energy and power, which relate energy and power to the weight of a battery, and the cycle life, which is the number of cycles that a battery can be charged and discharged before requiring replacement (Eudy \& Gifford, 2003). Table 1-3 provides the characteristics for a number of battery technologies. Li-ion batteries are the latest commercially viable battery technology battery technology and have been used extensively in consumer products. They offer promise for advancements in BEV technology because they allow for a longer traveling range with a lower battery pack weight (Eudy \& Gifford, 2003). In addition to these qualities, there are other factors that bear additional 
consideration such as memory effect, cost, and toxicity. Memory effect is an effect that results when batteries are charged after several shallow discharge cycles and can actually reduce the effective capacity of a battery. Li-ion consistently has emerged as the currently favored technology by most because it does not have the same toxicity issues as other technologies and it does not exhibit memory effect as strongly as $\mathrm{Ni}-\mathrm{MH}$; however, it is generally the most expensive battery type. For this reason, the technology is being used to power the next wave of electronics and EVs.

Table 1-3. Comparisons of Battery Technologies (Eudy \& Gifford, 2003)

\begin{tabular}{|l|c|c|c|}
\hline Technology & $\begin{array}{c}\text { Specific Energy } \\
\text { (Wh/kg) }\end{array}$ & $\begin{array}{c}\text { Specific Power } \\
\text { (W/kg) }\end{array}$ & Cycle Life \\
\hline Lead Acid & 35 & 200 & 800 \\
\hline $\begin{array}{l}\text { Nickel Metal } \\
\text { Hydride (Ni-MH) }\end{array}$ & $45-75$ & 850 & 900 \\
\hline Nickel Cadmium & 30 & 260 & 1000 \\
\hline $\begin{array}{l}\text { Sodium Nickel } \\
\text { Chloride }\end{array}$ & $95-115$ & $170-260$ & $1000-2500$ \\
\hline Lithium Ion & $100-158$ & $700-1300$ & $>1000$ \\
\hline
\end{tabular}

One of the reasons that EBs are not more prevalent in transit systems are the expenses related to their development. The market for transit buses is limited (1550 buses manufactured by the largest bus producer in the U.S. in 2001, compared to 5.5 million vehicles produced by General Motors for the same year) and as a result, there is less capital available for R\&D efforts (Eudy \& Gifford, 2003). In addition, the order sizes for buses utilizing new technology are typically small because transit agencies want to limit their risks before making a determination whether a technology could be adapted into their system, thus presenting an additional barrier to achieving economies of scale for alternative buses (Eudy \& Gifford, 2003). As a result, most EBs have been developed by small firms operating on funds provided by venture capitalists. 
The new technology also comes at a significant cost to transit agencies. When the Santa Barbara Metropolitan Transit District was considering purchasing two EBs in 2003, they received a bid of $\$ 580,000$ per bus (Callaghan \& Lynch, 2005). A standard 40-foot diesel bus costs just under $\$ 300,000$ per bus and adding the hybrid option costs an additional $\$ 100,000$ 200,000 (Eudy \& Gifford, 2003). Table 1-4 provides a capital cost comparison for various mass transit bus technologies for the vehicle alone, not including infrastructure investment.

Table 1-4. Comparisons of Transit Bus Technology Capital Cost (Callaghan \& Lynch, 2005; Eudy \& Gifford, 2003)

\begin{tabular}{|l|c|}
\hline Transit Bus Technology & $\begin{array}{c}\text { Cost per bus } \\
\text { (2003 dollars) }\end{array}$ \\
\hline Standard 40-foot Diesel Bus & $\$ 280-290 \mathrm{~K}$ \\
\hline CNG Bus (40-foot) & $\$ 300-320 \mathrm{~K}$ \\
\hline Diesel Hybrid Bus (40-foot) & $\$ 390-450 \mathrm{~K}$ \\
\hline Hybrid Shuttle bus (22-foot) & $\$ 260-350 \mathrm{~K}$ \\
\hline Battery Electric Shuttle Bus (22-foot) & $\$ 500-600 \mathrm{~K}$ \\
\hline Fuel Cell Bus & $\$ 3$ million \\
\hline
\end{tabular}

In addition to the high capital costs of acquiring new EBs, transit agencies are also faced with additional costs of equipment and training necessary to maintain the new buses (Eudy \& Gifford, 2003). Both General Motors and Nissan are introducing EVs into their portfolio for consumer vehicles. It is reasonable to assume that the popularity of these vehicles may increase the interest in EBs, which could bring additional investment and help to adjust the cost structure associated with developing and manufacturing EBs.

In addition to cost consideration, there are significant challenges with EB technology and unanswered questions regarding environmental impacts associated with their production and use. The most challenging issue with EBs is the limitation of range that is dictated by the battery size and technology. Transit agencies need to consider charging implications when planning bus routes, which may ultimately tip the scales in favor of the ICEB extended range capability. 
Depending on the availability of quick charging technology, it may not be feasible for one EB to fully replace the functionality of one ICEB. This may ultimately limit the acceptance of the technology without subsidies for transit agencies considering a transition to EBs. Also, the impacts of shifting pollution from diesel combustion at the bus to electricity production at power plants are unknown and may reduce certain pollutants at the expense of increasing others. There are, however, attributes that make EBs attractive for transit agencies. These include noise reduction, potential for reduced maintenance activities, and improved acceleration (Callaghan \& Lynch, 2005). Probably the most important benefit of EBs is the shift in the location of emissions from distributed sources in congested regions to localized point sources in less populated areas. Buses are operated on a fixed route and schedule which makes charging activities and planning more feasible than that for a vehicle with a highly variable location and schedule (Eudy \& Gifford, 2003). 


\subsection{LITERATURE REVIEW}

The literature review for this research focused on two main areas: mass transit LCA studies and Li-ion electric vehicle LCA studies. This section includes a summary of the literature that was reviewed for this research as well as a critique of the existing studies, which ultimately built the basis for the contributions of this study to the existing field of research.

\subsection{SUMMARY OF MASS TRANSIT AND EV STUDIES}

Ou et al. (2010) studied the life cycle GHG emissions and energy use for several alternative fuel buses for potential implementation in China from a well-to-wheels (WTW) perspective. The study, which included several different fuel technologies, including CNG, LNG, conventional diesel, diesel-hybrid, and electric, analyzed a theoretical bus of 12 meters in length and capable of carrying 70 passengers. Previous studies have focused on either well-to-pump (WTP), which comprises all of the upstream activities related to producing a fuel source, or pump-to-wheels (PTW) which comprises the emissions and energy consumption related to the use phase of a vehicle. This study divided the WTP portion into four different sub-stages: feedstock production, feedstock transportation, fuel production, and fuel transportation, storage, and distribution and assigned a mix of fuels needed for each of those sub-stages. The WTP and PTW energy use and GHG emissions were then summed for each of the different alternative fuel 
technologies considered. Sensitivity analyses were conducted to determine the impacts on fuel transportation distance and energy use in the fuel production stage on overall energy use and GHG emissions. Also, Ou et al. (2010) considered the addition of $\mathrm{CO}_{2}$ capture and storage (CCS) and its impact on electricity-related emissions.

Ally and Pryor (2007) conducted a study for the Sustainable Transport Energy Program for the government of Australia focusing on life cycle impacts of diesel, natural gas, and hydrogen fuel cell buses. The study focused on the fuel production impacts all the way back to natural resource extraction and also included the manufacturing differences between the three different bus types. A good portion of the study focused on the infrastructure and processes required to produce the hydrogen fuel and fuel cell stack for the hydrogen bus.

Wirasingha et al. (2008) conducted a feasibility analysis study for the transition to plug-in hybrid electric buses (PHEB) for the Chicago Transit Authority (CTA). They compared the impacts associated with the use of a PHEB to those of an ICEB, focusing only on fuel use, fuel cost, and $\mathrm{CO}_{2}$ emissions. Instead of focusing on the production of new buses, Wirasingha et al. (2008) proposed modifications to existing buses to add electric battery equipment at an estimated cost of $\$ 150,000$ per bus. Based on their case study for the CTA, they believe that the conversion of ICEBs to PHEBs could result in a reduction of 1.5 million lbs. of $\mathrm{CO}_{2}$ emissions per bus over its lifetime and an associated cost savings of $\$ 280,000$.

Chester et al. (2010) performed an LCA for existing transit modes in three different large metropolitan areas of the United States, New York City, Chicago, and Los Angeles. Unlike most transit studies which focus only on the use phase impacts of a particular combination of transport modes, this study also include all of the upstream impacts related to vehicle manufacturing, fuel extraction and manufacturing, and infrastructure. The transit habits of the three areas were 
ascertained by surveys conducted by the individual transit agencies in each city and indicated that the majority of transit in each location was by personal automobile and between 2.1 and 4.6\% of travel was via mass transit buses. This study focused on the following emissions utilizing a hybrid LCA approach: GHGs, $\mathrm{CO}, \mathrm{NO}_{\mathrm{x}}$, sulfur dioxide $\left(\mathrm{SO}_{2}\right)$, PM10, and volatile organic compounds (VOCs).

The results of the study showed that indirect emissions (those not directly associated with the use phase) contributed a significant amount to the overall emissions for all of the transit modes studied (Chester, et al., 2010). Specifically, the life-cycle GHG, $\mathrm{NO}_{\mathrm{x}}$, and VOC emissions were $50 \%$ larger than for just the use phase. Chester et al. (2010) indicate that even though mass transit emissions are dwarfed considerably by those from personal automobiles, they still command consideration because if passenger habits could be adjusted to add additional ridership to the existing mass transit system, significant GHG reductions could be achieved.

Samaras et al. (2008) performed a study to compare the life cycle energy use and GHG emissions for three cars with different drivetrain technologies: internal combustion engine vehicle (ICEV), HEV, and PHEV. Previous studies on HEVs and PHEVs neglected the energy use and emissions related to the battery manufacturing portion of the life cycle (Samaras \& Meisterling, 2008). Data from the study was compiled from existing LCAs, EIO-LCA outputs for the vehicle manufacturing impacts, and literature estimations for the impacts related to battery manufacturing. This study focuses on Li-ion batteries because of the shift towards that technology from other less successful technologies like Ni-MH and lead acid. The study provides a range of battery weights $(75-250 \mathrm{~kg})$ depending on the desired range of the vehicle (30-90 km). In addition, sensitivity analyses were performed to understand the implications of changing the power generation portfolio in the United States. 
Notter et al. (2010) performed a study to compare the life cycle impacts of a BEV to an ICEV in the following categories: GWP, cumulative energy demand (CED), EcoIndicator 99 using hierarchic perspective and average weighting, resource depletion as measured by abiotic depletion potential (ADP), and emissions of $\mathrm{PM}_{10}, \mathrm{NO}_{\mathrm{x}}$, and $\mathrm{SO}_{2}$. The study focuses most closely on the production of the Li-ion battery, but also includes the vehicle use and manufacturing stages. A theoretical vehicle deemed to be technically feasible was the basis for the study. The study made implicit assumptions about the battery manufacturing process to result in the highest burdens for batteries.

McCleese and LaPuma (2002) conducted an LCA to evaluate the life cycle emissions and energy use between an ICEV and three different BEVs, each powered by a different battery technology, lead-acid, nickel-cadmium, and Ni-MH. They study included both the manufacturing and use phases of the vehicles and neglected vehicle assembly and end-of-life concerns related to battery disposal. The EIO-LCA tool was used to account for the supply chain effects related to the fuel for the ICEV. A Monte Carlo analysis was utilized to ensure the wide range of emissions factors associated with different ICEVs were captured in the assessment (McCleese \& LaPuma, 2002).

Matheys et al. (2007) studied the influence of the choice of functional unit on the outcomes of LCA studies related to BEVs. Specifically, the study focuses on the following three functional units: battery packs with identical mass, battery packs with identical energy content, and battery packs with identical one-charge range. EcoIndicator 99 was used as the impact assessment tool to compare the different battery technologies. The same car model was assumed for all of the battery cases, so the upstream impacts related to the car manufacturing were consistent across the studied scenarios (Matheys, et al., 2007). 
Tzeng et al. (2005) performed a study utilizing 11 decision making-criteria (including energy efficiency, noise pollution, costs of implementation and maintenance, and comfort) to compare 12 different alternative fuel bus technologies (including CNG, LNG, electric, and methanol). The study relied on experts from different specialties to rank each of the bus technologies for each of the attributes (Tzeng, et al., 2005). Unfortunately, the specifics of the different bus technologies that were evaluated were not specifically discussed.

Silva et al. (2009) evaluated the different methods that can be used to calculate fuel consumption and emissions factors associated with PHEVs. There is no widely established and accepted method for calculating these values for PHEVs. In particular, there is little consistency on assumptions related to PHEVs. The differences in emissions factors and fuel consumption calculations stem from assumptions about the appropriate split of ICE and battery that are used to power the PHEV (Silva, et al., 2009).

Shiau et al. (2009) studied the effects of battery size and weight on vehicle performance and GHG emissions from PHEVs. In addition, they considered the effects of adding structural support (steel) to the vehicle to accommodate for the added weight of the battery pack (Shiau, et al., 2009).

\subsection{COMPARISON OF LIFE CYCLE RESUTLS FROM LITERATURE}

\subsubsection{ICEB and EB LCA Study Results from Literature}

Two of the studies reviewed (Ou et al. (2010) and Chester and Horvath (2009a)) compared the life cycle environmental impact of ICEBs with that of EBs. Ou et al. (2010) determined the 
following emissions and energy use figures for the ICEB and EB (for the use-phase only): 1700 and $1500 \mathrm{~g} \mathrm{CO}_{2}, \mathrm{e} / \mathrm{km}$ and 21 and $17 \mathrm{MJ} / \mathrm{km}$. The electricity mix that was used in the study was representative of what currently exists in China: $80.1 \%$ coal, $1.8 \%$ oil, $0.7 \%$ natural gas, $1.9 \%$ nuclear, $0.1 \%$ biomass, and 14.7\% from other sources. Ally and Pryor (2007) utilized a lower number for the ICEB energy efficiency, $17 \mathrm{MJ} / \mathrm{km}$.

While the LCA conducted by Ou et al. (2010) included well-to-wheel considerations for the alternative fuel buses study, it neglected the production of the buses themselves. It is likely that the buses may be very similar structurally; however there are certainly different impacts that should be considered relative to the battery production processes that are unique to EBs. The study by Chester and Horvath (2009a) included all of the upstream impacts associated with the bus in addition to the use-phase. Figures 2-1 and 2-2 show the energy use and GHG emissions assumed for the use phase for the ICEB and EB in each of the three studies. While the values do not match exactly, they are consistent and the differences are likely due to assumptions made about the particular bus being analyzed.

Ou et al. focused only on GHG emissions and fossil energy use, while Chester and Horvath expanded the scope of the study to include other pollutants like $\mathrm{NO}_{\mathrm{x}}, \mathrm{SO}_{2}, \mathrm{VOC}$, and $\mathrm{PM}_{10}$. As indicated by Figure 2-1and Figure 2-2, Ou et al. found that the ICEB had higher energy use and higher GHG emissions, while Chester and Horvath found that the EB had higher energy use and the ICEB had higher GHG emissions. Chester and Horvath found that the ICEB had higher emissions for all of the other criteria pollutants except for $\mathrm{SO}_{2}$. 


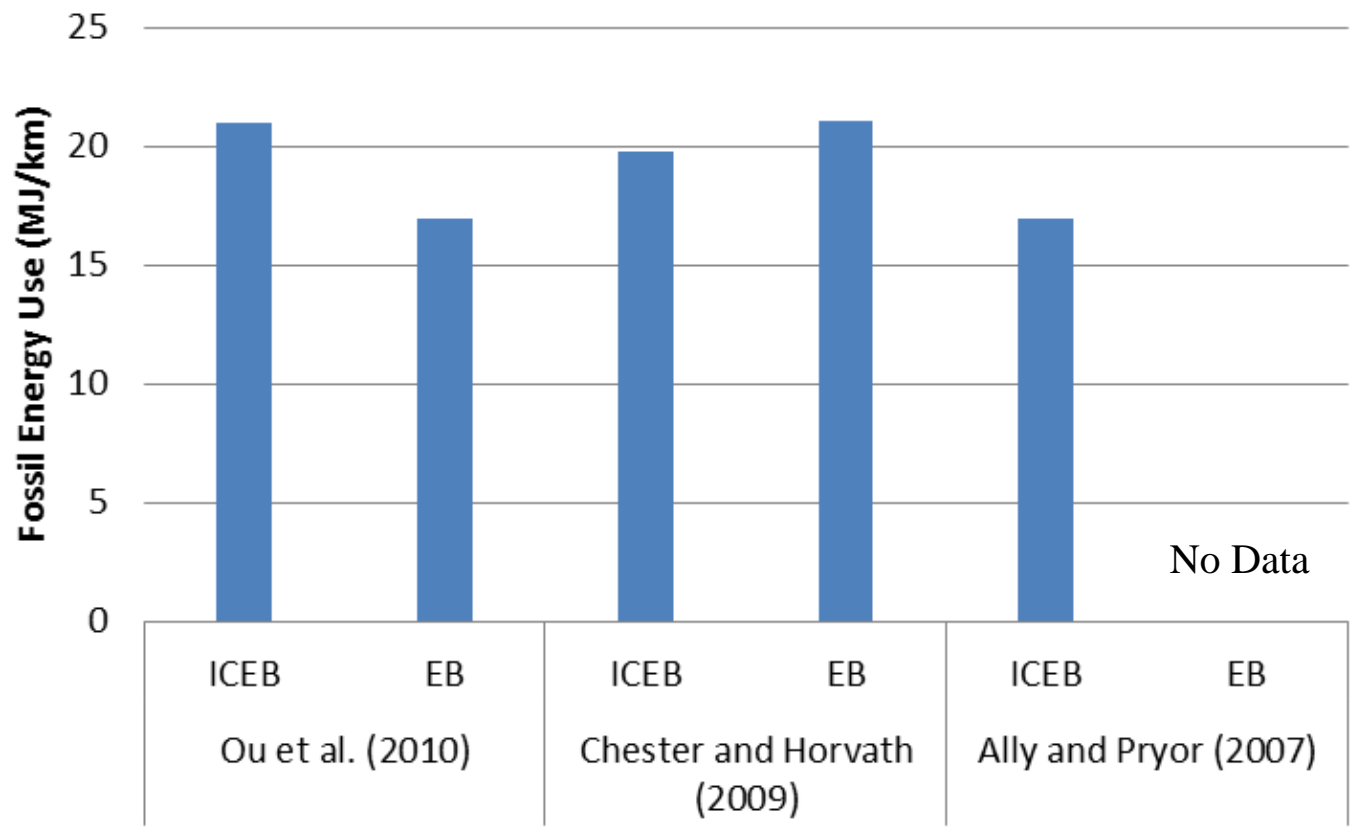

Figure 2-1. Comparison of ICEB and EB energy use (MJ/km)

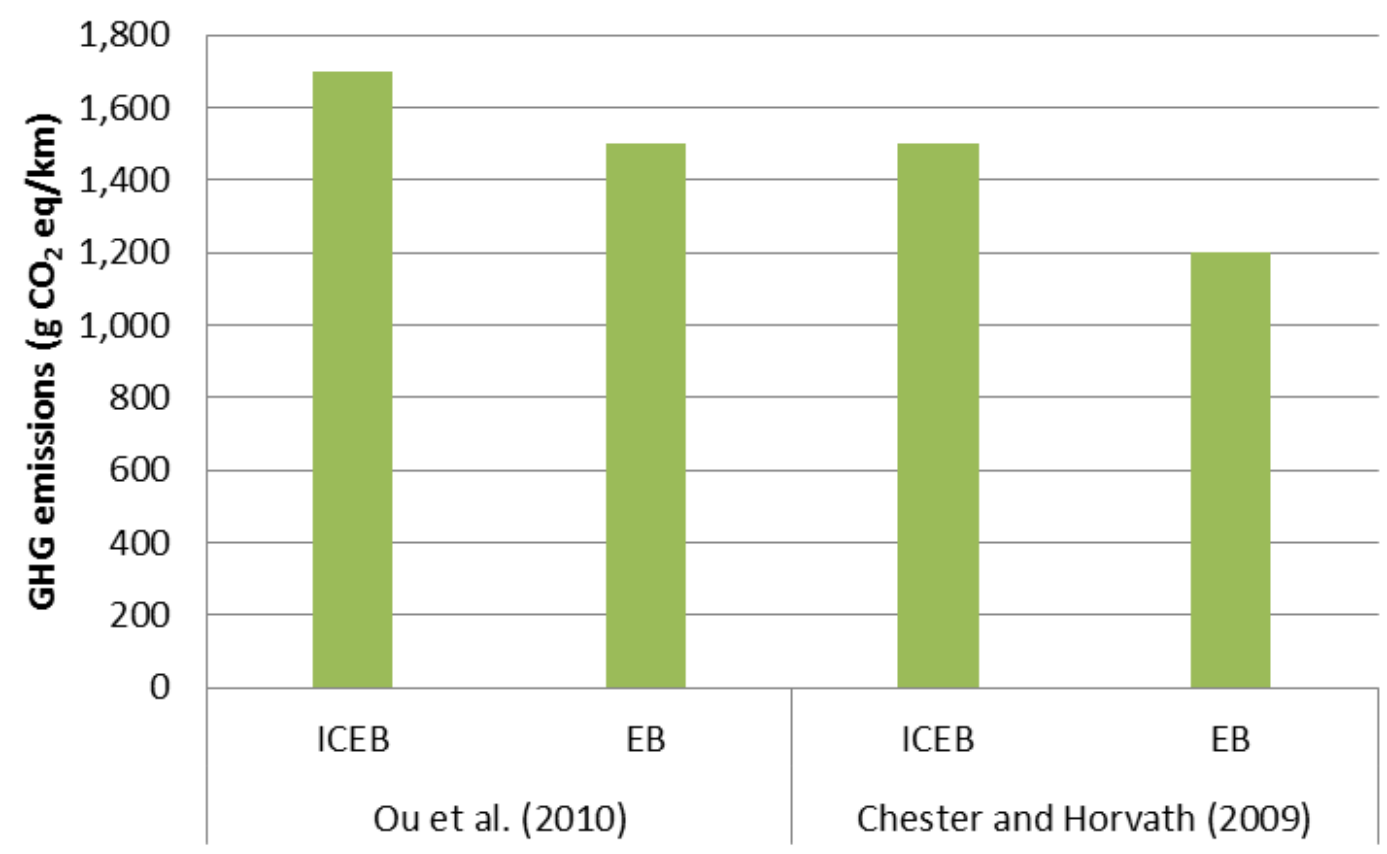

Figure 2-2. Comparison of ICEB and EB GHG emissions ( $\left.\mathrm{g} \mathrm{CO}_{2}, \mathrm{e} / \mathrm{km}\right)$ 


\subsubsection{EV Battery LCA Studies from Literature}

Notter et al. (2010) compared a BEV with an ICEV on the basis of GWP, CED, EcoIndicator 99, and ADP, while Samaras and Meisterling (2008) compared PHEVs with various ranges to a HEV and an ICEV on the basis of GHG emissions and energy use. In both studies, the energy use and environmental impacts of the EV were less than those for the ICEV and the impacts attributed to the Li-ion battery component of the study were small compared to the use-phase energy related emissions. According to the Samaras and Meisterling study, PHEVs reduce lifetime GHG emissions by 32\% compared to IC vehicles, but have minimal improvements over HEVs given the existing electricity production mix in the United States (670 $\mathrm{g} \mathrm{CO}_{2}, \mathrm{e} / \mathrm{kWh}$ ). Sensitivity analyses were performed to look at how changes in the electrical grid might affect the results of the study. In a low-carbon scenario (200 $\mathrm{g} \mathrm{CO}_{2}, \mathrm{e} / \mathrm{kWh}$ ), use of PHEVs bring extensive reductions in GHG emissions, between 30-60\% when compared to HEVs and ICEVs (Samaras \& Meisterling, 2008).

The Notter et al. (2010) study showed that the environmental impacts attributed to the Liion battery production were relatively small (7-15\%, depending in impact factor) compared to the other life cycle contributions from the operation and manufacturing of the cars. The study assumed that there were no differences between the ICEV and BEV when it came to the infrastructure impacts. The process LCA performed on the Li-ion battery indicated that the impacts related to the production of the battery were primarily from the production of the cathode, anode, and battery pack (Notter, et al., 2010).

Samaras and Meisterling (2008) provided the background that is necessary to scale up a Li-ion battery to provide a reasonable range estimate for a mass transit bus. In addition, they provided some estimates of energy inputs necessary to produce each kWh of battery storage 
(1700 MJ of primary energy to produce one kWh of Li-ion battery capacity). One assumption that is made for simplification in their study is that the difference between the size of the IC engines on an ICEV and a HEV are offset by the electric motor and control equipment on the HEV/PHEV. One difference between the Samaras and Meisterling study and this study is that the EB is a fully battery-powered electric vehicle, not a hybrid vehicle which also has an IC engine. The Notter et al. (2010) study was performed on a technically feasible theoretical vehicle, which is similar to the basis for this study since there is no publicly available data regarding the technical specifics of EBs. Supporting information that is available with this study provides the basis for specifics on energy consumption for the given size and range of the vehicle that was the subject of the LCA.

Majeau-Bettez et al. (2011) performed a LCA study that assessed the life cycle impacts Ni-MH and Li-ion batteries. The study was critical of the upstream production energy assumptions made by Notter et al. (2010) and Samaras and Meisterling (2008) and calculated life cycle GHG emissions that were two to four times higher than those previously reported in the literature. Majeau-Bettez et al. calculated GHG emissions of $22 \mathrm{~kg} \mathrm{CO}$,e per $\mathrm{kg}$ of Li-ion battery, whereas Notter et al. and Samaras and Meisterling reported 6.0 and $9.6 \mathrm{~kg} \mathrm{CO}$,e per $\mathrm{kg}$ of Li-ion battery respectively.

McCleese and LaPuma (2002) conducted an LCA to compare the emissions (GHGs, $\mathrm{NO}_{\mathrm{x}}, \mathrm{SO}_{2}$, CO, VOCs) and life cycle energy use for an ICEV and three different types of EVs (lead-acid, nickel-cadmium, Ni-MH). Their study concluded that a nationwide shift from ICEVs to EVs in the United States would result in an increase in GHGs, $\mathrm{NO}_{\mathrm{x}}$, and $\mathrm{SO}_{2}$, while a reduction would be seen for energy use, $\mathrm{CO}$, and VOCs. These results contradict the findings of Samaras and Meisterling (2008) and Notter et al (2010). However, it is important to note that 
McCleese and LaPuma completed their study at the beginning of the decade and did not include Li-ion batteries as potential sources of power in EVs. It is clear in the literature that Li-ion batteries are the most advanced technologically and offer the greatest promise for applications in EVs because of their high energy density, so while the McCleese and LaPuma results are interesting, they are nonetheless dated. The results of the study by Matheys et al. (2007) confirm the results of Samaras et al. and Notter et al., in that the Li-ion battery has the lowest environmental impact when compared to all of the other battery types. That study did not, however, compare any of the batteries to an ICEV, so it is not possible to either confirm or question the results from the McCleese and LaPuma study.

\subsection{CRITIQUE OF LITERATURE}

Ou et al. (2010) and Chester and Horvath (2009a) were the only two studies that actually presented data and results for environmental impacts of EBs. Both studies can serve as a comparison basis for this study; however, it is important to note the limitations that will prevent those studies from being used as direct comparisons to these results. Ou et al. (2010) did not consider the manufacturing of the EB components, so this study will likely result in higher emissions and energy use if the electricity mix is normalized for both studies. In addition, Ou et al. did not consider the charging infrastructure required for the operation of EBs. These impacts are necessary for a complete study. Although it is outside the scope of this LCA, the Ou et al. study provides comparisons to other alternative fuel buses. There are limitations with the study, however, because of different assumptions about efficiencies used in the fuel production and electricity production processes. 
Chester and Horvath (2009a) utilized EIO-LCA to calculate the environmental impact associated with the manufacture, maintenance, and insurance of the EB, however, they assumed that the cost of an EB is $\$ 350,000$. This is significantly less than other estimates for EBs (\$580,000 for a 22 -foot bus) and is not much of a premium over the cost of conventional diesel buses (\$300,000) (Callaghan \& Lynch, 2005; Eudy \& Gifford, 2003). It is possible that this assumption will result in a dramatic understatement of the inventory estimates for the EB and adjustments will be necessary before an adequate comparison can be made. The study also presents values for energy use and GHG emissions during the use phase for both the EB and conventional diesel bus. These values can be utilized for comparison purposes with my own study.

Other studies focused on ICEBs, not EBs; however, they will serve as a good comparison basis for the emission factors and environmental impacts that are attributed to the ICEB in this model. The Ally and Pryor (2007) study was unique in that it provided information regarding environmental impacts beyond just GWP. Unlike Ou et al. (2010), Ally and Pryor (2007) included the manufacturing impacts for the buses themselves and this can serve as a good comparison to judge the validity of my results for the conventional diesel bus. The results will have to be adjusted slightly based on the electricity mix that is used in Australia compared to that in the United States.

Similar to the EIO-LCA results for the EB, the study by Chester and Horvath (2009a) also provides information on infrastructure, vehicle manufacturing, and maintenance for the diesel bus. The study also assumes that the vehicle lifetimes and weights of the EB and diesel bus are equivalent. This assumption may need further consideration since the addition of battery packs to the EB may cause it to end up weighing slightly more than an equivalent diesel bus. It 
is unclear whether or not the charging infrastructure associated with the EB is considered in this study or not. If not, additional infrastructure impacts would need to be added to the values presented in the study.

The findings of the Silva et al. (2009) study are important to consider when referencing emissions factors for PHEVs. The vehicle in my study will likely be a BEV; however, it is still important to understand that the method in which emissions factors are calculated can vary substantially depending on the method used and assumptions made.

Neither the Tzeng et al. (2005) nor the Wirasingha et al. (2008) studies will be useful for the context of my project. Tzeng et al. (2005) did not provide any technical specifics for any of the bus technologies discussed, so I cannot review their assumptions and design for the EB in particular. Also, their study relied on a number of factors that are outside the scope of an LCA, including cost, noise, and comfort. The CTA study conducted by Wirasingha et al. (2008) considered on $\mathrm{CO}_{2}$ emissions based on the use-phase of the bus and neglected the entire upstream infrastructure. Also, the study discusses the idea of converting existing ICEBs to PHEBs by adding the necessary electrical infrastructure to the buses; however, the impacts associated with the new equipment are never discussed. The study provided useful background information for an understanding of mass transit systems, but I think this is all it was useful for. It could not be used for any sort of real-world comparison of the two different technologies. However, I do think that the idea of converting existing ICEBs to PHEBs is an interesting idea that does bear some additional study.

Three of the studies reviewed focused closely on the different battery technology that may be utilized by BEVs. Both Notter et al. (2010) and Samaras and Meisterling (2008) compared BEVs to ICEVs with a specific focus on the contributions of the Li-ion battery pack to 
the overall life cycle environmental impacts. McCleese and LaPuma (2002) compared the environmental impacts of five different kinds of battery technologies. While none of these studies is an exact match to what I am doing, they have provided important information about assumptions that I will need to make to successfully complete my study.

Samaras and Meisterling provided the background that is necessary for me to scale up a Li-ion battery to provide a reasonable range estimate for a mass transit bus. In addition, they provided some estimates of energy inputs necessary to produce each kWh of battery storage (1700 MJ of primary energy to produce one kWh of Li-ion battery capacity) (Samaras \& Meisterling, 2008). One assumption that is made for simplification in their study is that the difference between the size of the IC engines on an ICEV and a HEV are offset by the electric motor and control equipment on the HEV/PHEV (Samaras \& Meisterling, 2008).

One difference between the Samaras and Meisterling (2008) study and mine is that I will focus on a fully battery-powered electric vehicle, not a hybrid vehicle which also has an IC engine. Therefore, I think that I can use the results of their study as an order of magnitude check for differences between the IC vehicle and the HEVs. In the study, it was assumed that electricity was used to power the PHEVs for $47-76 \%$ of the miles traveled. I think that it may be possible to scale the results from their study to provide another scenario for a PHEV that is powered by electricity $100 \%$ of the time, essentially making it a BEV. This way, I can use the difference between the ICEB and BEV as a comparison for my own study when I look at the differences between an ICEB and EB. I can also use the results from the sensitivity studies that were performed to analyze the effects of different carbon mixes for the electrical production in the United States on the benefits of PHEVs to ICEVs. 
The Notter et al. (2010) study was performed on a technically feasible theoretical vehicle, which is similar to the basis for my study since there is no publicly available data regarding the technical specifics of EBs. Supporting information that is available with this study provides the basis for specifics on energy consumption for the given size and range of the vehicle that was the subject of the LCA. This will be particularly important in scaling up a battery pack to provide a reasonable range for the EB in my study. Unlike many of the other studies that I found, the Notter et al. paper (2010) evaluates the environmental impacts of EVs beyond CED and GWP. This will serve as an important comparison basis for my study when I compare the results of the ICEB and EB. Similar to the other studies, there was no discussion of attributing emissions or energy demand to the charging infrastructure that would be likely necessary to support a mass transition to BEVs. The study looked closely at the impacts of the each of the components in the Li-ion battery. This information is valuable in terms of stating assumptions, but altering the battery materials or chemistry is beyond the scope of my LCA study when considering the EBs.

The findings by McCleese and LaPuma (2002) were interesting in that they show the progress that has been made in battery technology when the results are compared to those from Samaras and Meisterling (2008) and Notter et al. (2010). It would be inappropriate to compare the results of my study to those of McCleese and LaPuma (2002) since their analysis did not include Li-ion batteries. It is, however, important to be aware that the old technology used for EV batteries may have had deleterious impacts on the energy use and the environment, counter to what many would think. The results of the study by Matheys et al. (2007) confirm the results of Samaras and Meisterling and Notter et al., in that the Li-ion battery has the lowest environmental impact, as measured by Eco-indicator 99, when compared to all of the other 
battery types. That study did not, however, compare any of the batteries to an ICEV, so it is not possible to either confirm or question the results from the McCleese and LaPuma study.

The Matheys et al. (2007) study is important to my analysis because there is an extensive discussion of the advantages and disadvantages of the different functional units proposed for studying EVs in LCA. This will help me to determine which functional unit is appropriate for my own study, but more importantly, I will understand the critical assumptions and limitations of that functional unit. In addition, although they did not determine that there was a significant difference between the environmental impact results in their study, they did note that there is significant variation in the literature that can alter the ranking of battery technologies. This will be particularly important when it comes to validating and potentially comparing my results to existing studies. One criticism of the study is that the details regarding the specifics of the batteries considered in the study were not provided explicitly in the article. The study included assembly and manufacturing of the battery components in the LCA; however, it did not provide any insight to the materials used in each of the different batteries. 


\subsection{LIFE CYCLE ASSESSMENT OF TRANSIT BUSES}

\subsection{INTRODUCTION}

\subsubsection{Significance of environmental impacts of buses}

In 2005, there were approximately 50,000 diesel powered public transit buses operating in the United States, consuming over 500 million gallons of fuel annually (Wayne \& Sandoval, 2007). Almost 22 billion passenger-miles were traveled by bus in 2005 yielding an average efficiency of 44 passenger-miles per gallon of fuel (American Public Transportation Association, 2010), and mass transit buses averaged 2.8 to 3.4 miles per gallon of diesel fuel (Wayne \& Sandoval, 2007). As a result of the combustion process, transit buses account for 5.9 million metric tons of $\mathrm{CO}_{2}$, 59,000 metric tons of $\mathrm{NO}_{\mathrm{x}}, 14,000$ metric tons of $\mathrm{CO}, 2,400$ metric tons of non-methane hydrocarbons and 1,300 metric tons of PM emitted to the atmosphere on an annual basis (Wayne \& Sandoval, 2007).

Even though buses only represent $1 \%$ of all of the transportation vehicles in the United States, they account for $44 \%$ of the 50 billion public transit passenger-miles annually since they often operate in dense urban centers (American Public Transportation Association, 2010; Eudy \& Gifford, 2003). The Clean Air Act (1990) identifies diesel powered motor vehicles, including transit buses, as significant sources of several criteria pollutants which contribute to ground level 
ozone formation or smog. The effects of air pollution in urban areas are often more significant due to congestion and can lead to respiratory and cardiovascular health impacts. As a result, many transit agencies have considered migrating to other types of fuels and bus technologies that result in less air pollution emissions. According to the American Public Transportation Association (2010), in 2009, 30\% of the buses in the United States were using some type of alternative fuel technology (diesel hybrid, biodiesel, compressed natural gas (CNG), liquefied natural gas (LNG), propane, and battery electric.

This study focuses on a comparison of the life cycle environmental impacts from conventional diesel internal combustion engine buses (ICEBs) with those associated with battery electric buses (EBs). In addition to shifting emissions from distributed tailpipes to power plant point sources, there are battery production impacts that must also be considered when examining a proposed conversion of bus technology.

Electric-powered buses have been in operation in the United States since the 1800s, mostly trolley-style vehicles powered by an overhead catenary line (Callaghan \& Lynch, 2005). ICEBs eventually became the predominant technology because they offered more route flexibility than the fixed-route trolley buses. Battery-powered buses are a relatively new development and have only been commercially available since the late 1990s (Callaghan \& Lynch, 2005). As of 2005, there were 90 - 120 EBs operating in the United States, with the majority of these operating as 22-foot shuttle buses in niche markets with limited routes (Callaghan \& Lynch, 2005).

There are significant challenges with EB technology and unanswered questions regarding environmental impacts associated with their production and use. The most challenging issue with EBs is range dictated by the battery size and technology. Transit agencies need to consider 
charging implications when planning bus routes, which may ultimately tip the scales in favor of the ICEB extended range capability. There are, however, attributes that make EBs attractive for transit agencies. These include noise reduction, potential for reduced maintenance activities, and improved acceleration (Callaghan \& Lynch, 2005). Buses are operated on a fixed route and schedule which makes charging activities and planning more feasible than that for a vehicle with a highly variable location and schedule (Eudy \& Gifford, 2003).

The drivetrain for a battery electric vehicle (BEV) consists of three major systems that replace the internal combustion engine (ICE) in a conventional vehicle: (1) electric motor, (2) battery pack (3) control system (Callaghan \& Lynch, 2005). As a result of their design, BEVs are able to achieve high torque at low speeds, which makes them particularly attractive for mass transit bus applications because of the frequent stops for passenger drop-off and pickup (Callaghan \& Lynch, 2005).

\subsection{BACKGROUND AND LITERATURE REVIEW}

\subsubsection{Mass Transit Studies}

Relatively few mass transit LCAs have examined the differences between an ICEB and an EB. Ou et al. (2010) and Chester and Horvath (2009b) compared the life cycle environmental impact of ICEBs with that of EBs. Ou et al. determined emissions for the ICEB and EB for the usephase of 1,700 and $1,500 \mathrm{~g} \mathrm{CO}_{2} \mathrm{e} / \mathrm{km}$, respectively, although the predominantly coal-fired electricity mix that was used in the study was representative of what currently exists in China. 
The LCA conducted by Ou et al. included well-to-wheel considerations for the alternative fuel buses study, but did not include production impacts for the vehicles or components.

The study by Chester and Horvath included all of the upstream impacts associated with the bus in addition to the use-phase. The GHG emissions assumed for the use phase for the ICEB and EB in the Chester and Horvath study were 1,500 $\mathrm{g} \mathrm{CO}_{2} \mathrm{e} / \mathrm{km}$ for the ICEB and 1,200 $\mathrm{g}$ $\mathrm{CO}_{2} \mathrm{eq} / \mathrm{km}$ for the EB. Chester and Horvath utilized EIO-LCA to calculate the environmental impact associated with the manufacture, maintenance, and insurance of the EB, and assumed that the capital cost of the EB was $\$ 350,000$ (2009b). The study also assumes that the vehicle lifetimes and weights of the EB and diesel bus are equivalent.

\subsubsection{Li-ion LCA studies form literature}

Considerable attention in the literature is focused on LCA evaluations of EVs, specifically regarding the life cycle implications of the Li-ion battery production. Notter et al. (2010) compared a BEV with an internal combustion engine vehicle (ICEV), while Samaras and Meisterling (2008) compared plug-in hybrid electric vehicles (PHEVs) with various ranges to a hybrid electric vehicle (HEV) and an ICEV. In both studies, the energy use and environmental impacts of the EV were less than those for the ICEV and the impacts attributed to the Li-ion battery component of the study were small compared to the use-phase energy related emissions. According to the Samaras and Meisterling study, PHEVs reduce lifetime GHG emissions by 32\% compared to ICE vehicles, but have minimal improvements over HEVs given the existing electricity production mix in the United States $(670 \mathrm{~g} \mathrm{CO} 2 \mathrm{e} / \mathrm{kWh})$. Sensitivity analyses were performed to look at how changes in the electrical mix might affect the results of the study. In a 
low-carbon scenario (200 $\mathrm{g} \mathrm{CO}_{2} \mathrm{e} / \mathrm{kWh}$ ), use of PHEVs bring extensive reductions in GHG emissions, between 30-60\% when compared to HEVs and ICEVs.

The Notter et al. (2010) study showed that the environmental impacts attributed to the Liion battery production were relatively small (7-15\%, depending in impact factor) compared to the other life cycle contributions from the operation and manufacturing of the cars. The study assumed that there were no differences between the ICEV and BEV when it came to the infrastructure impacts. The process LCA performed on the Li-ion battery indicated that the impacts related to the production of the battery were primarily from the production of the cathode, anode, and battery pack.

One simplifying assumption which is made in the Samaras and Meisterling study is that the difference between the size of the IC engines on an ICEV and a HEV are offset by the electric motor and control equipment on the HEV/PHEV. The Notter et al. study was performed on a technically feasible theoretical vehicle, which is similar to the basis for this study since there is no publicly available data regarding the technical specifics of EBs. The results of the study by Matheys et al. (2007) confirmed the results of Samaras et al. and Notter et al., in that the Li-ion battery has the lowest environmental impact when compared to all of the other battery types.

More recently, Majeau-Bettez et al. (2011) performed a LCA study that assessed the life cycle impacts Ni-MH and Li-ion batteries. The study incorporated industry-specific data regarding the production energy required for final manufacturing of the finished battery pack. Based on this additional data, the calculated life cycle GHG emissions that were two to four times higher than those previously reported in the literature. Majeau-Bettez et al. calculated 
GHG emissions of 22 kg $\mathrm{CO}_{2} \mathrm{e}$ per kg of Li-ion battery, whereas Notter et al. and Samaras and Meisterling reported 6.0 and $9.6 \mathrm{~kg} \mathrm{CO}_{2} \mathrm{e}$ per $\mathrm{kg}$ of Li-ion battery respectively.

This study adds to the existing literature by utilizing process LCA methods to more completely model the manufacturing impacts of the Li-ion batteries installed onboard the EB and the required battery replacements over the projected lifetime of the vehicle. Similar to the studies by $\mathrm{Ou}$ et al. and Chester and Horvath, this study also includes the production and use-phase impacts for the vehicles. In addition, this study evaluates the preference for bus technology as a function of the carbon intensity of the electricity grid. It should be noted that this study did not rely on data from the Argonne National Lab Greenhouse gases, Regulated Emissions, and Energy use in Transportation (GREET) model (ANL, 2006). Upon review of the GREET model for Li-ion batteries, it was determined that the more recent work by Majeau-Bettez et al. (2011) was more comprehensive and consistent with other recently published LCA work on Li-ion batteries by Notter et al. (2010), and Samaras and Meisterling (2008).

\subsection{METHOD}

\subsubsection{Goal and Scope}

The goal of this LCA study is to compare the ICEB and EB life cycle environmental impacts, including the production of the bus and battery, as well as the use phase impacts from either diesel production/combustion or electricity generation. Based on a review of transportation electrification studies in the literature, it was desirable to expand the environmental impact calculations beyond just global warming potential (GWP) to include ozone depletion, particulate 
formation, ecotoxicity, and acidification impacts. While there are definite similarities between the ICEB and EB, the goal of this study is to show the scale of the additional battery production and charging infrastructure impacts on the entire life cycle of the vehicle. Sensitivity analysis was used to understand the importance of the electricity mix, EB battery life, and EB charging patterns on the comparison of the two bus technology platforms.

The functional unit for this study is 1 vehicle-kilometer over a 12 year lifetime. The study did not use passenger-kilometers as the functional unit since it was assumed that both bus platforms provide identical functionality and capacity. According to the Federal Transit Administration (FTA), most transit agencies utilize a 12 year lifetime for buses and this is the estimate that is utilized in government reports concerning transit vehicles (Clark, Zhen, Wayne, \& Lyons, 2007; 2007). Chester and Horvath (2009b) calculated life cycle energy and emissions inventories for various transportation modes, including buses and one of the default functional units that they utilized was vehicle lifetime. The effect of assuming a prescribed lifetime should have minimal impact on the results since it is assumed that both the ICEB and EB have the same lifetime. Given the state of production and implementation of EBs, there is no basis for assuming otherwise.

\subsubsection{System Boundary Selection}

Figure 3-1 depicts the process flow chart utilized for the LCA study as well as the system boundary which details the unit processes that were included and excluded from the scope of the study. It was assumed for this study that the EB and ICEB are built utilizing the same bus shell, interior fittings and components. If EBs are widely commercialized in the future, there may be some differences in the actual shell and interior, for example additional structural support or 
interior modifications to accommodate the Li-ion battery and electric drive system components. It is unlikely that these differences would alter the results of the LCA study significantly. The primary difference between the physical bus models is that the ICEB has a diesel engine (and supporting components), while the EB has a battery and an electric drive system. The EB also requires a charging infrastructure to facilitate the reliability of the bus operation. The dominant portion of the study is the use phase of the buses. For the ICEB the use phase is dominated by diesel combustion, while the EB use phase is controlled by the impacts from electricity production. This study also includes the maintenance impacts for both types of buses as well as the charging system.

The environmental impacts related to the roadway construction, maintenance, and disposal were not included in the study boundary because it was assumed the impacts were identical for both the ICEB and EB, since for the base case both vehicles were assumed to have approximately identical weights. The end-of-life impacts for the bus shell, components, and batteries were also excluded based on a lack of data. It is evident that a recycling infrastructure for Li-ion batteries from EBs could reduce the life cycle impacts that are attributed to the batteries; however, the particular impacts are difficult to model without additional data. This assumption was consistent with the studies performed by Samaras and Meisterling (2008), Notter et al. (2010), and Majeau-Bettez et al (2011). Based on these assumptions, the system boundary was set such that it included the manufacturing and use-phase impacts for the ICEB and EB. 


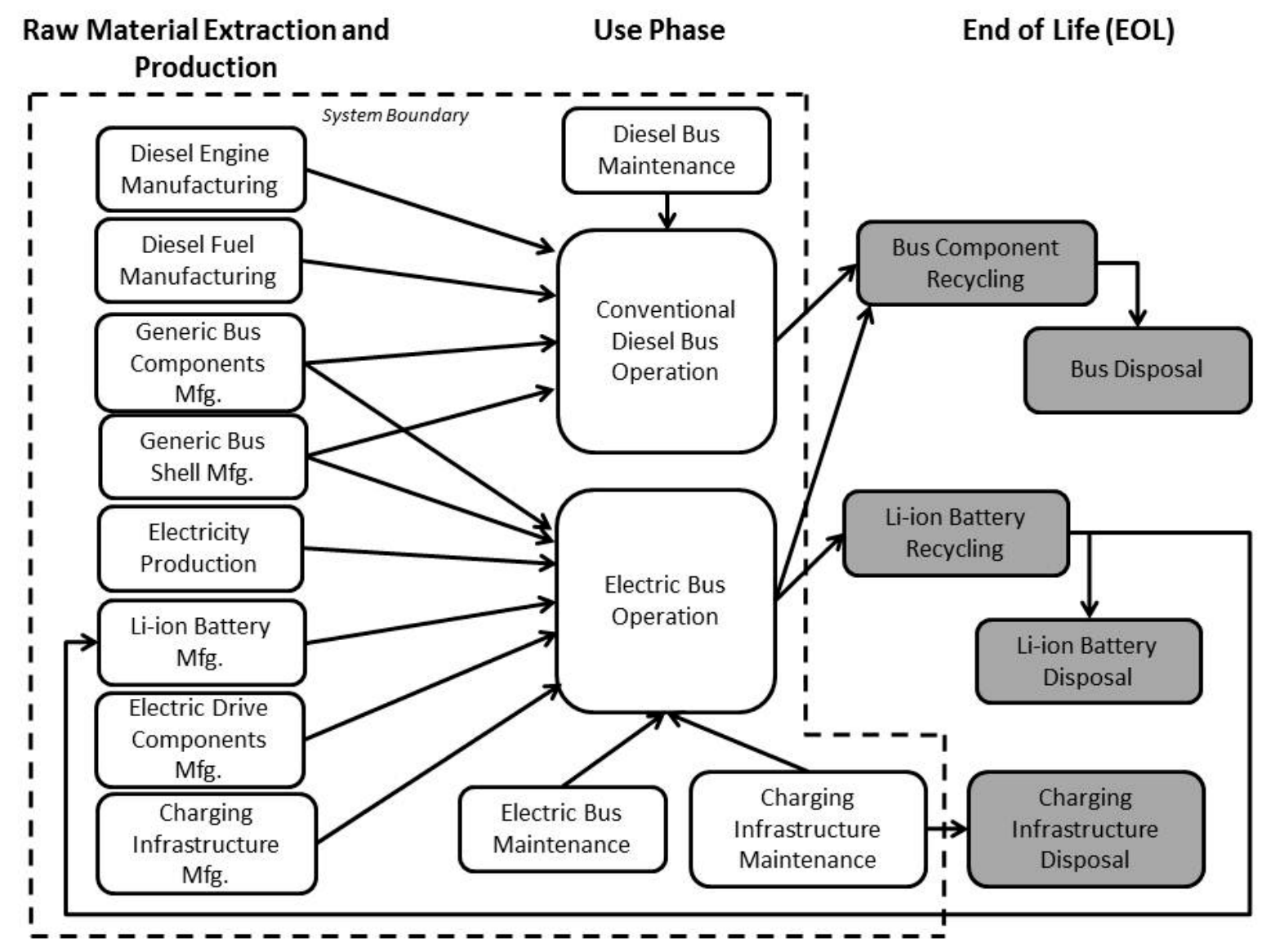

Figure 3-1. LCA study process flow chart and system boundary

\subsubsection{System Processes and Data Sources}

The LCA for this study was completed by combining three different data sources, the USLCI database, the Ecoinvent v2.2 database and the Carnegie Mellon University Green Design Institute EIO-LCA tool (2008; Hischier, et al., 2010; NREL, 2004). The processes shown in Figure 3-1 for the life cycles of the ICEB and EB were categorized into the following five contributions: shell, maintenance, battery, charging infrastructure, and use phase. The bus shell included the manufacturing impacts for the physical exterior of the vehicle, any components necessary to operate the vehicle (tires, suspension, lights, wiring, etc.), and all of the interior 
furnishings. In addition, for the ICEB, the shell included the diesel engine and drivetrain components and for the EB the shell included the electric motor and all of the electric drivetrain and control components. The LCI data for the bus shell was determined by utilizing the EIOLCA tool for North American Industry Classification System (NAICS) sector 336120, Heavy Duty Truck Manufacturing. The bus model utilized for the shell is a standard 40-foot mass transit bus that can be found in operation in almost every urban area in the U.S. It was assumed that the ICEB and EB could hold the same number of passengers and that both vehicles have identical functionality. Based on these characteristics, it was assumed that one EB could replace one ICEB and could be utilized in the same manner for the transit agency.

Maintenance activities for the ICEB were assumed to include oil changes and routine component replacements required over the 12 year life of the vehicle. Based on FTA estimates for diesel hybrid buses, it was assumed that the EB would yield a 25\% reduction in maintenance costs over the lifetime because of the elimination of some activities that are unique to the ICEB (Clark, et al., 2007). The maintenance process category was modeled in the EIO-LCA tool for NAICS sector 81111, Automotive Repair and Maintenance.

The battery and charging infrastructure categories were unique to the EB, therefore they do not contribute to the ICEB emissions inventory. The charging infrastructure was modeled using the EIO-LCA tool with purchases from NAICS sector 335999, Miscellaneous Electrical Equipment and Power Supply Component Manufacturing. The Majeau-Bettez et al. (2011) process LCA of a Li-ion battery was utilized as the framework for modeling the life cycle impacts of the EB battery. The model was developed using system processes available in the EcoInvent v2.2 database for $1 \mathrm{~kg}$ of Li-ion battery and then was scaled up to fit the EB battery size requirements (Hischier, et al., 2010). 
LCI data for diesel fuel production/combustion and electricity generation was obtained from the USLCI databases (NREL, 2004). This portion of the model was categorized as the usephase and consisted of either diesel production/combustion for the ICEB or electricity generation and transmission for the EB. The electricity generation inventory from USLCI accounts for line losses of 9.9\%. It was assumed that the existing electricity generation capacity could support the additional demand imposed by the electrification of half of the mass transit bus fleet and thus, no infrastructure or capital impacts related to additional generation capacity were included in this study. This finding was consistent with a study by Denholm and Short (2006) which analyzed the effect of a 50\% conversion of the U.S. automobile fleet to PHEVs assuming smart charging. Table 3-1 indicates the tools and databases utilized to model the five components of the bus life cycle. Table 3-2 includes the data sources and values that were utilized as inputs to EIO-LCA or were used to derive fuel and electricity consumption during the use phase of the vehicles. Additional information regarding model inputs, assumptions, and sources is available in Appendix A.

Table 3-1. LCI Data Collection

\begin{tabular}{|l|c|}
\hline \multicolumn{1}{|c|}{ LCA Sub-Process } & Tool/Database \\
\hline $\begin{array}{l}\text { Transit bus shell and } \\
\text { component }\end{array}$ & EIO-LCA \\
\hline Maintenance & EIO-LCA \\
\hline Battery & $\begin{array}{r}\text { Process LCA/Eco-Invent and } \\
\text { USLCI databases }\end{array}$ \\
\hline Charging Infrastructure & EIO-LCA \\
\hline Use Phase & Process LCA/USLCI database \\
\hline
\end{tabular}


Table 3-2. LCI Data Sources

\begin{tabular}{|c|c|c|}
\hline $\begin{array}{c}\text { Process or Data } \\
\text { Requirement }\end{array}$ & Value(s) Used in LCA Model & Source \\
\hline $\begin{array}{l}\text { Transit bus shell and } \\
\text { component details and } \\
\text { cost }\end{array}$ & $\$ 300,000$ per bus & $\begin{array}{l}\text { (Clark, et al., 2007; Cummins } \\
\text { Engines, 2010; Eudy \& Gifford, } \\
\text { 2003; Laver, et al., 2007) }\end{array}$ \\
\hline Transit bus lifetime & 12 years; 37,000 miles per year & $\begin{array}{l}\text { (Callaghan \& Lynch, 2005; Chester } \\
\text { \& Horvath, 2009b; Laver, et al., } \\
\text { 2007) }\end{array}$ \\
\hline $\begin{array}{l}\text { ICEB engine efficiency } \\
\text { fuel energy content }\end{array}$ & $\begin{array}{l}\text { 45\% efficient; } 132,000 \\
\text { BTU/gallon of diesel fuel }\end{array}$ & $\begin{array}{l}\text { (DOE, 2000; ICF International, } \\
\text { 2009) }\end{array}$ \\
\hline ICEB fuel efficiency & 3.1 miles per gallon & $\begin{array}{l}\text { (American Public Transportation } \\
\text { Association, 2010; Callaghan \& } \\
\text { Lynch, 2005; Clark, et al., 2007) }\end{array}$ \\
\hline ICEB maintenance costs & $\$ 66,500 /$ year (2007 dollars) & (Clark, et al., 2007) \\
\hline EB maintenance costs & $\$ 50,000 /$ year (2007 dollars) & (FTA, 2007b) \\
\hline $\begin{array}{l}\text { EB operations and } \\
\text { charging details }\end{array}$ & 90\% efficient (charger) & $\begin{array}{l}\text { (Bennion \& O'Keefe, 2010; Bubna, } \\
\text { Brunner, Gangloff Jr, Advani, \& } \\
\text { Prasad, 2010; Callaghan \& Lynch, } \\
\text { 2005; Chester \& Horvath, 2009b; } \\
\text { Eudy \& Gifford, 2003; Wayne \& } \\
\text { Sandoval, 2007) }\end{array}$ \\
\hline EB motor efficiency & $\begin{array}{l}\text { 75\% efficient (MJ electricity } \\
\text { converted and delivered to } \\
\text { drivetrain) }\end{array}$ & $\begin{array}{l}\text { (Majeau-Bettez, et al., 2011; Notter, } \\
\text { et al., 2010; Samaras \& Meisterling, } \\
\text { 2008) }\end{array}$ \\
\hline $\begin{array}{l}\text { Li-ion battery } \\
\text { specifications }\end{array}$ & 112 Wh/kg; 3000 cycles & $\begin{array}{l}\text { (Bennion \& O'Keefe, 2010; Majeau- } \\
\text { Bettez, et al., 2011; Notter, et al., } \\
\text { 2010; Samaras \& Meisterling, 2008) }\end{array}$ \\
\hline
\end{tabular}

For the purposes of this study, it was assumed that the electric motor and drive components on the EB are equal in environmental impacts to the diesel engine and supporting components on the ICEB. This simplification was necessary because a detailed component list for an EB does not exist. Samaras and Meisterling (2008) made a similar assumption in their LCA study of PHEVs. As with other EVs, the size of the battery determines the range of the vehicle. For the base case, it was assumed that the EB battery size was equal in weight to the diesel engine and fuel that is displaced, meaning that it could weigh up to $1,800 \mathrm{~kg}$. It is possible that a larger (heavier) battery could be installed on the bus without additional structural 
modifications; however, for the purposes of the base case, the simplification was made to limit it to $1800 \mathrm{~kg}$. Equation 1 shows how the lifetime electricity requirement was calculated for the EB from characteristics of the ICEB operation. $\eta_{f}-$ Diesel Fuel Efficiency (miles/gal); $\eta_{d}-$ Diesel Engine Thermal Efficiency (\%); $\rho_{\mathrm{d}}-$ Diesel Fuel Energy Content (BTU/gal); D - Lifetime Operation (miles); $\eta_{\mathrm{e}}-$ Electric Drive Efficiency (\%); $\eta_{\mathrm{c}}-$ Charger Efficiency (\%); W Conversion Factor (kWh/BTU)

$$
E B=\left[\frac{1}{\eta_{f}}\right]\left[\eta_{d}\right]\left[\rho_{d}\right][D]\left[\frac{1}{\eta_{e}}\right]\left[\frac{1}{\eta_{c}}\right] W
$$

It was assumed that quick charging of the EB will be possible. This simplification was made for the base case because it was assumed that one EB could replace one ICEB. This means that charging can take place during layover time at the end of the route without impacting the ability of the bus to provide its necessary function for the transit agency. This assumption is highly dependent on the type of service that the EB is utilized in as well as the state of charging technology. Based on the battery size and required daily energy demand, it was determined that the EB must stop for charging four times per day, meaning that the battery pack must be replaced five times over the 12 year life cycle. The manufacturing impacts of the additional battery packs are included in the life cycle emissions calculations and the replacement activities are considered to be included in the EB maintenance services.

\subsection{RESULTS}

The life cycle processes depicted in the Figure 3-1 system diagram were categorized into five different categories: bus shell, maintenance, battery, charging infrastructure, and use phase. 
Figure 3-2 shows the lifetime environmental impact results for both the ICEB and EB in 11 different categories based on the assumptions detailed in Section 3.3. This study utilized IMPACT 2002 to categorize the environmental impacts from the LCI data (Jolliet, et al., 2003). IMPACT 2002 was chosen as the LCIA tool so that data output from EIO-LCA, which is only reported as the midpoint results utilizing IMPACT 2002, could be added to the process LCA results. The use phase, whether it is diesel production/combustion for the ICEB or electricity generation for the EB assuming the current U.S. grid average, dominates most of the impact categories. The EB has the added impacts from the Li-ion battery and charging infrastructure production.

Battery production is an important factor in several of the impact categories, making the ICEB preferable with respect to ozone depletion potential, carcinogenics, and ecotoxicity measures. The ecotoxicity categories carry much more uncertainty than the others because of the domination of the impacts by a single element, cobalt. The cobalt releases are a byproduct of the production of the positive electrode of the battery, which contains a mixture of lithium, nickel, cobalt, and manganese. Based on the dominance of cobalt, in the IMPACT 2002 tool, the interpretation of the ecotoxicity results are less certain than other categories with more established and agreed upon characterization factors. The ozone depletion impact category is dominated by battery production and upon closer inspection of the individual sub processes is dominated by CFC and HCFC releases during the manufacturing of the positive and negative electrodes. The carcinogens category is also dominated by battery production; however, the impacts a spread across several of the battery manufacturing sub processes. The chemicals that dominate this category include arsenic, cadmium, chromium, dioxins, and aromatic hydrocarbons. In general, the impacts related to the bus maintenance operations for the ICEB 
and EB and the charging infrastructure for the EB are diminished by impacts from the other processes.

Additional information regarding the LCIA results is located in Appendix B.

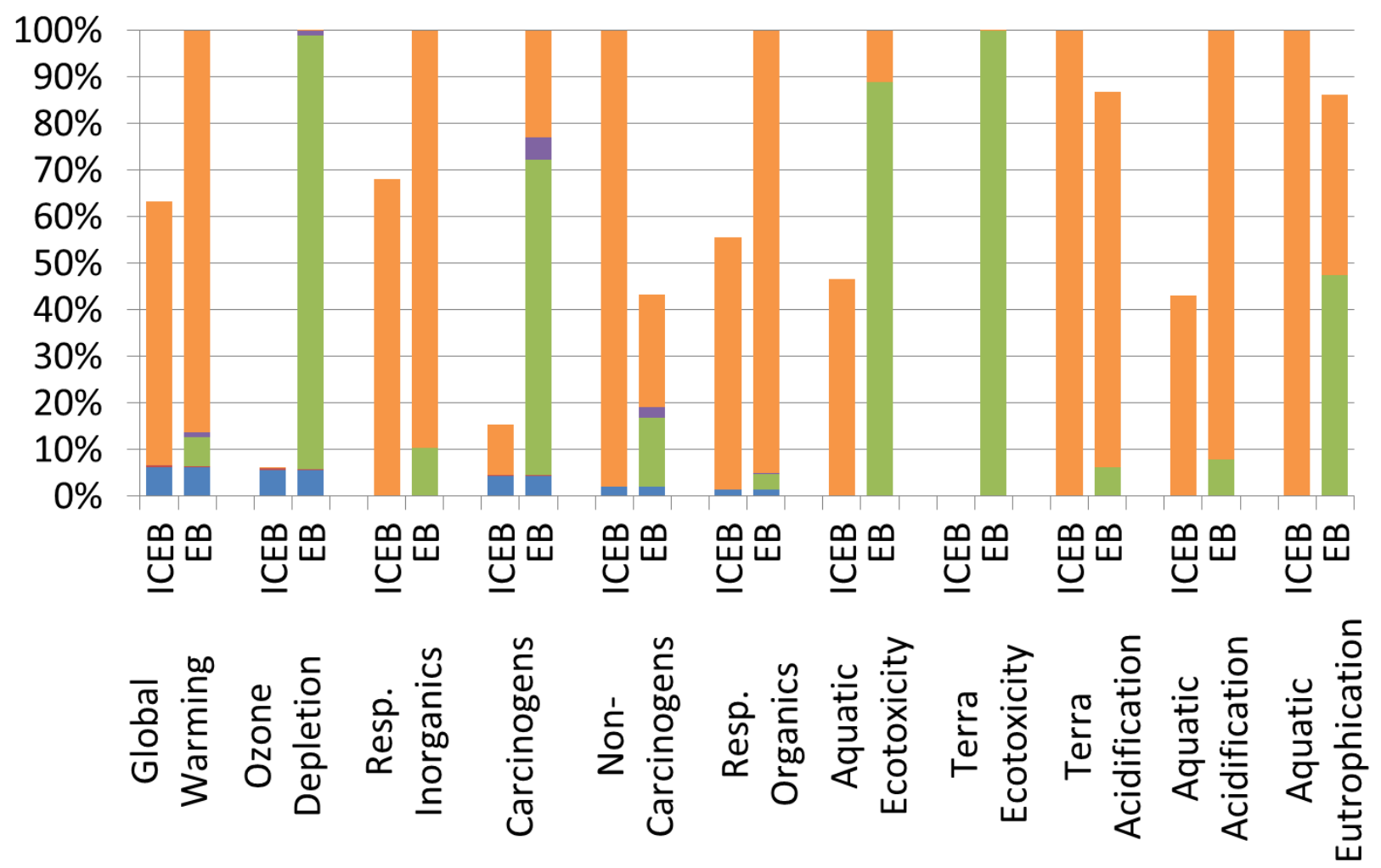

Shell $\square$ Maintenance $\square$ Battery $\square$ Charging Infrastructure $\square$ Use Phase

Figure 3-2. Life Cycle Assessment Results for Base Case

Normalized to Highest Impact in Category; ICEB - Internal Combustion Engine Bus; EB - Electric Bus

As discussed in Section 3-2, studies conducted by Ou et al. (2010) and Chester and Horvath (2009) calculated life cycle GHG emissions estimates for an ICEB and an EB. The average emissions for the studies were 1,600 g CO $2 \mathrm{e} / \mathrm{km}$ for the ICEB and 1,350 g $\mathrm{CO}_{2} \mathrm{e} / \mathrm{km}$ for the EB. The results for this study were $80 \%$ higher for the ICEB and $235 \%$ higher for the EB. These results are not surprising since Ou et al. did not include production impacts for the EB 
battery and Chester and Horvath assumed that EBs cost only 15\% more to produce than ICEBs, which is a small premium compared to other estimates in the literature (Callaghan \& Lynch, 2005; Eudy \& Gifford, 2003). In addition, neither study considered the implications of required battery replacements over the lifetime operation of the vehicles. While it is not explicitly stated, it is possible that the Chester and Horvath study utilized the carbon dioxide emission factor for the state of California, which is significantly lower than the U.S. average and would tend to shift the preference toward the EB. This study utilized the average U.S. electricity grid, which has a higher carbon dioxide emission factor because of the significant presence of coal power generation at near 50\%. The impact of electricity grid is discussed further in Section 3.5. This study also found the opposite of the previous conclusions in the literature. The EB resulted in higher GHG emissions than the ICEB when utilizing the average electricity grid mix for the U.S.

These results differ from those of Samaras and Meisterling in that they indicated a slight preference for the battery electric vehicle over the conventional fossil fuel powered vehicle with respect to GHG emissions. As illustrated by Figure 3-2, there is considerable uncertainty in the overall preference for bus platform when considering all environmental impacts together. The major difference is that this is a comparison of a diesel powered vehicle with an battery electric vehicle, whereas those studies compared a gasoline powered vehicle with a battery electric vehicle. The conventional diesel engine is more efficient than a gasoline engine and diesel fuel has $10 \%$ higher energy content per gallon compared to gasoline; however, diesel also has higher carbon content. These differences shift the preference from the battery electric vehicle to the diesel vehicle in this study. In addition, most of the studies from the literature either do not consider battery replacement or assume only one additional battery during the lifetime of the 
vehicle. Due to the service and charging requirements for the EB in this study, five battery replacements are required, which adds significantly to the life cycle GHG emissions.

Figure 3-3 shows the use phase air emissions of four EPA criteria pollutants collected directly from the life cycle inventory of the study. The EB use phase includes emissions from both electricity generation and Li-ion battery production. The ICEB use phase includes diesel production and combustion emissions. The figure illustrates that the ICEB has higher $\mathrm{CO}, \mathrm{NO}_{\mathrm{x}}$, and $\mathrm{PM}_{10}$ emissions, while the $\mathrm{EB}$ has higher $\mathrm{SO}_{\mathrm{x}}$ emissions. Similar to Figure 3-2, this illustrates the tradeoffs between bus technologies depending on the environmental impact of concern.

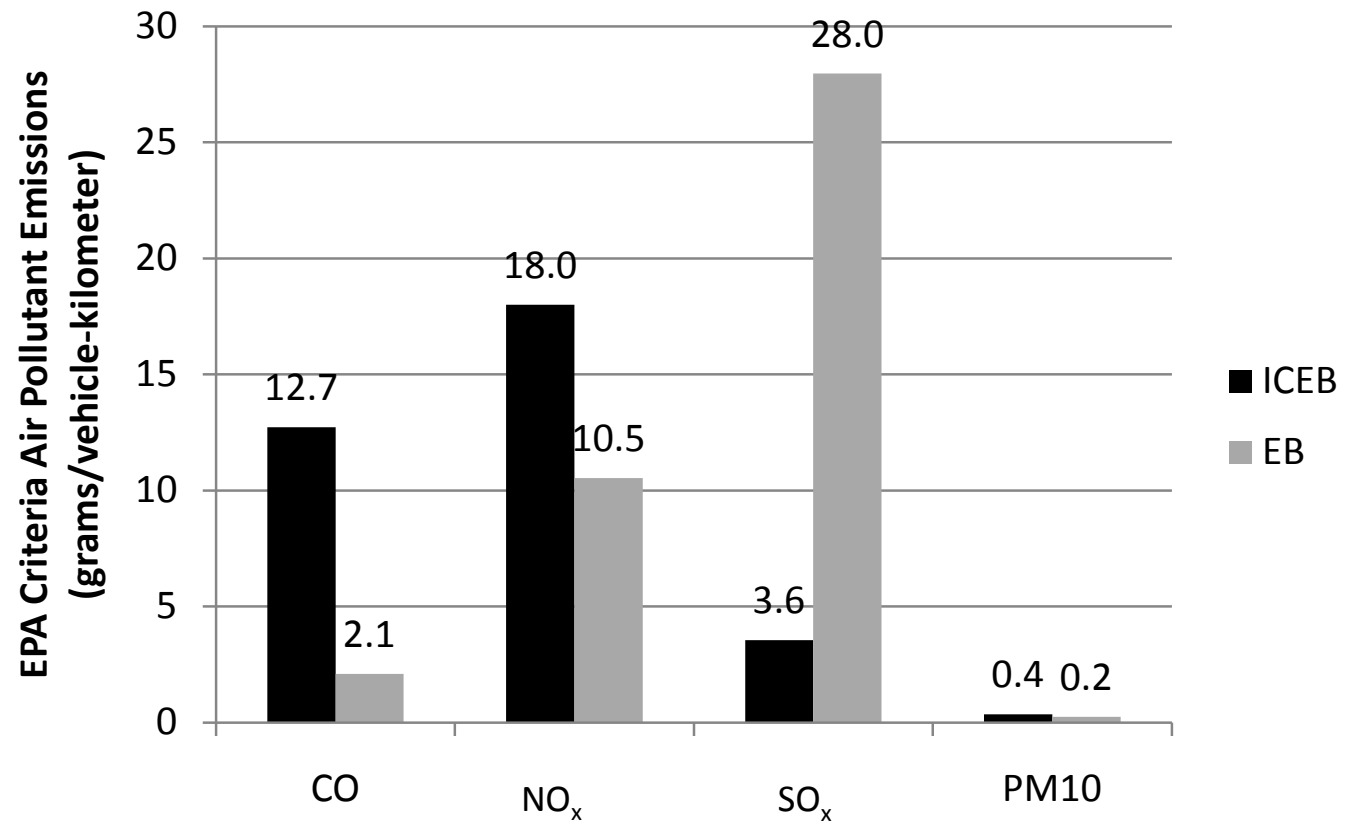

Figure 3-3. Use phase emissions of EPA criteria pollutants per vehicle-kilometer Includes electricity generation and battery production for EB and diesel production and combustion for ICEB.

The studies by Samaras and Meisterling and Notter et al. estimated life cycle GHG emissions of 9.6 and $6.0 \mathrm{~kg} \mathrm{CO}_{2} \mathrm{e} / \mathrm{kg}$ of Li-ion battery produced. Modeled after the process LCA 
developed by Majeau- Bettez et al., this study calculated battery production impacts to be 17.1 $\mathrm{kg} \mathrm{CO}_{2} \mathrm{e} / \mathrm{kg}$ of Li-ion battery produced, which is higher than the other estimates based on differences in modeling the manufacturing energy required to produce the battery. As shown by Figure 3-2, the impacts from battery production are important to some of the environmental impact categories, including global warming. If the study relied on the smaller battery production GHG emissions presented in the literature, the preference for the ICEB in terms of global warming impact would not change significantly.

\subsection{SENSITIVITY ANALYSIS OF KEY PARAMETERS}

\subsubsection{Electricity Grid Impact}

One of the assumptions made in the base case of the model was that the electricity grid was comprised of the average provided in the USLCI database (51\% coal, 19\% nuclear, 16\% natural gas, 3\% fuel oil, 7\% hydropower, $4 \%$ other). As shown in Figure 3-2, the use phase dominates for both the ICEB (diesel production/combustion) and the EB (electricity generation). The impacts of electricity production methods were examined further and the results are provided in Figure 3-44. Figure 3-44 shows that the preference for bus platform with respect to GWP is highly dependent on the carbon emissions factor for a given method of electricity production (Hondo, 2005; Jaramillo, Griffin, \& Matthews, 2007; NREL, 2004; Weisser, 2007). The carbon intensity of the U.S. average electricity grid in 2009 is shown as a point on the figure as well as the EIA projection of the grid composition in 2035. A grid powered by predominantly by renewables or nuclear results in a strong preference for the EB over the ICEB in terms of GHG 
emissions. This is an important consideration for policy applications because regional variations may result in a preference for the EB in one area of the country, while other areas with more carbon dense methods of electricity production would yield a preference for the ICEB.

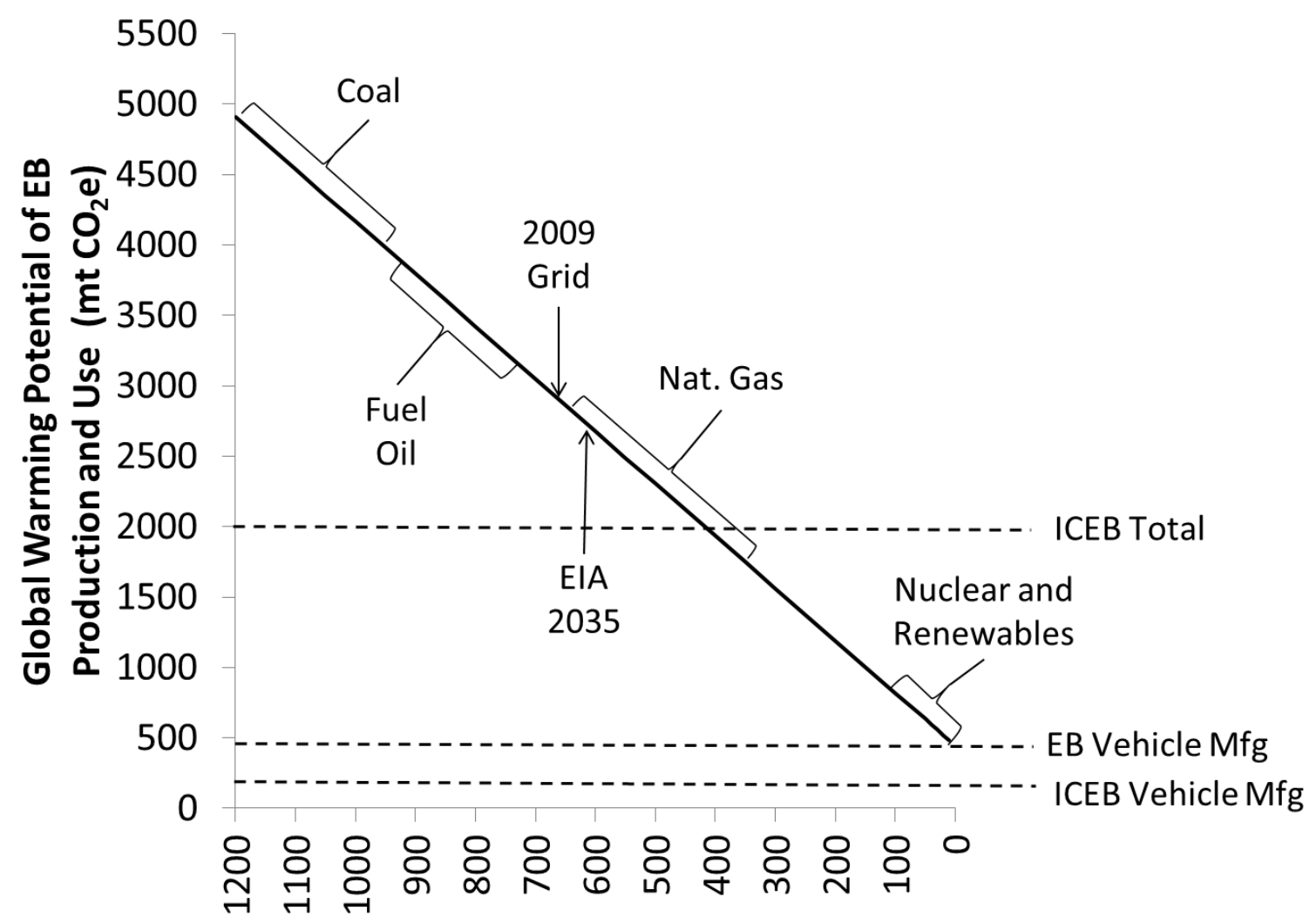

\section{Life Cycle Carbon Intensity of Electricity Grid $\left(\mathrm{g} \mathrm{CO}_{2} \mathrm{e} / \mathrm{kWh}\right)$}

Figure 3-4. Production and Use Phase Life Cycle Assessment Global Warming Impacts as a Function of the Carbon Intensity of the Electricity Grid

Total Life Cycle ICEB Emissions Shown for Comparison; Various Generation Types Depicted with Carbon Intensity Values Found in Literature; “EIA 2035” Indicates the Energy Outlook Grid Projected for the Year 2035; ICEB - Internal Combustion Engine Bus; EB - Electric Bus; ICEB Base includes shell manufacturing and maintenance; EB Base includes shell, battery, and charging infrastructure manufacturing and maintenance; ICEB Total includes ICEB Base plus use phase emissions.

Decisions regarding public transit are typically made at the state and local levels, so it is important to consider the carbon intensity of the electricity grid on a regional basis to assess which bus technology is preferable in terms of global warming potential. State-level electricity generation mixes are published on an annual basis by the EPA; however, it is difficult to know 
the actual electricity generation portfolio with certainty because of the effects of interstate electricity trading. Marriott and Matthews (2005) developed a model to account for interstate trading of electricity and thereby calculate a more accurate electricity consumption mix for each state. These consumption mixes, which are available in Appendix $\mathrm{C}$ were utilized to determine the state-by-state preference for the EB or ICEB on the basis of GWP. The use phase emissions for the ICEB were compared to the battery production and use phase emissions for the EB.

Figure 3-55 shows the results of this analysis. The GWP preference for the preferred bus platform is displayed as a ratio of life cycle use phase GHG emissions of the EB to ICEB. For the EB use phase, battery replacements, in addition to electricity consumption were included in the calculation. Therefore, values less than one indicate that the EB would result in lower life cycle GHG emissions than the ICEB, while values greater than one imply that the ICEB would have lower life cycle GHG emissions. There are only eight states where using an EB would reduce GHG emissions compared to an ICEB with the given the current electricity mix for those states. Oregon and Washington use large amounts of hydro power at approximately $72 \%$ and $75 \%$ of their respective state electricity mixes. Therefore, there is a strong preference for the EB in those states since hydro power results in much lower GHG emissions than fossil-derived power. Utah and Wyoming rely heavily on coal derived electricity at $95 \%$ and $96 \%$ of the respective state electricity mixes. The carbon intensity for each state based on the interstate trade model and the comparison between the ICEB and EB platforms is available in Appendix D.

As illustrated in Figure 3-44, coal derived electricity produces significantly higher GHG emissions than the break even for the EB and ICEB. Thus, there is a strong preference for the ICEB in those states in terms of life cycle GHG emissions. In general, states that have significant contributions from nuclear and hydro power are more likely to show a preference for the EB over 
the ICEB. There is additional regional variation in electricity grid makeup within states; however, this analysis could provide a starting point for transit agencies that are evaluating policies and technologies to reduce $\mathrm{CO}_{2}$ emissions.

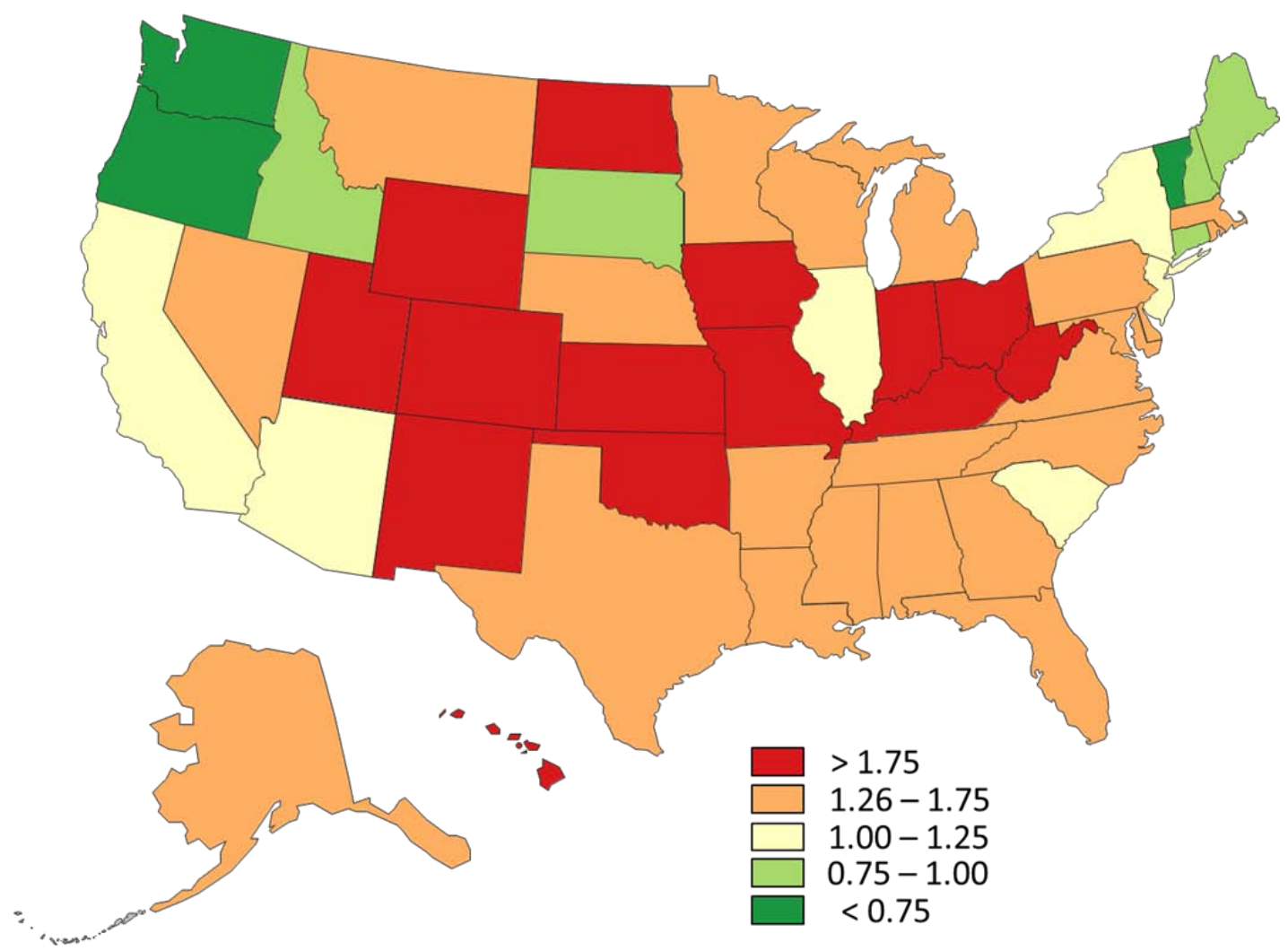

Figure 3-5. State-by-State Preference for EB or ICEB Accounting for Electric Grid Differences and Measured as EB Fraction of ICEB Lifetime $\mathrm{CO}_{2}$ Emissions

Values Less Than 1 Indicate that the EB is Preferred; ICEB - Internal Combustion Engine Bus; EB - Electric Bus

\subsubsection{Li-ion Battery Technology Impacts}

In addition to changes to the electricity grid, there are improvements that can be made to the EB to reduce the impacts of battery production. Battery technology has improved dramatically over the last century it is reasonable to assume that strides will continue to be made with respect to cycle life and energy density. A 25\% increase in the energy density of Li-ion batteries from 112 $\mathrm{Wh} / \mathrm{kg}$ to $140 \mathrm{Wh} / \mathrm{kg}$ would result in a $1.1 \%$ reduction in global warming, $1.7 \%$ reduction in 
particulate matter, and 16\% reduction in ozone depletion potential. Doubling the cycle life of the battery from 3,000 cycles to 6,000 halves the required battery replacements over the lifetime of the EB. This results in a 2.5\% reduction in global warming, $4.5 \%$ reduction in particulate matter, and 39\% reduction in ozone depletion potential. The base case of the study assumed that efficiency of the electric drive system was $75 \%$. An increase in efficiency to $80 \%$ results in a $11 \%$ reduction of global warming, $12 \%$ reduction in particulate matter, and a $9 \%$ reduction in ozone depletion potential. All of these improvements are substantial; however, the use phase of the EB dominates most impact categories and without changes to the predominant electricity production methods, the preference for either bus platform is unclear. Additional information regarding these sensitivity studies related to the Li-ion battery is located in Appendix E.

\subsection{DISCUSSION AND FUTURE WORK}

The discussion and future work section of the proposed journal paper have been relocated to Section 4.0 of this thesis to avoid repetition. 


\subsection{CONCLUSIONS AND FUTURE WORK}

Gaines and Cuenca (2000) noted that the major opportunities for price reductions for Li-ion batteries are likely to come from substitution of less expensive materials and improvements in production efficiency and scale. Materials constitute $75 \%$ of the cost of Li-ion batteries; however, production scale has been shown to have a significant influence on the finished battery cost. Advancements in sustainable battery production may also reduce the production impacts. The dominant cathode materials currently utilized for Li-ion batteries are cobalt, manganese, and nickel; however, there is considerable research into the use of organic materials in place of metals in the cathode (Armand \& Tarascon, 2008). In their LCA of Li-ion battery production for EVs, Notter et al. (2010) showed that the production of the cathode is the most energy intensive process. It is possible that the substitution of organic materials may reduce the overall energy demand required for battery production which would yield lower GHG emissions. It is difficult to determine the exact improvements as the research is being conducted on a small scale.

Another important consideration for reducing material and energy requirements for battery production is the incorporation of recycled spent Li-ion batteries, however, the exact reductions are unknown at this time. Rydh and Sanden (2005) estimated that the energy reduction for the production of recycled in place of virgin Li-ion battery materials may be as much as $50 \%$. While this figure is significant, the LCIA showed that batteries contributed to a measurable extent in certain impact categories. It is unlikely that the addition of recycling would 
change the result of the preference for the ICEB in terms of global warming, for example. Recycling is important, however, when considering issues like resource depletion. This study did not focus on resource depletion; however, widespread adoption of EVs could dramatically impact the reserves of the cathode metals, specifically nickel, cobalt, and manganese. Recycling of Li-ion batteries would certainly dampen this impact compared to the use of only virgin metals.

As discussed in Section 1.4, one of the barriers to implementation of EBs is the associated capital costs related to the vehicle and infrastructure as well as increased operating costs during the first couple of years of operation to support training of mass transit operators and technicians. As with most technologies, improvements in the production of Li-ion batteries should drive down costs associated with EBs; however, a significant portion of the cost is dependent on the volatility of the metals markets since the primary costs associated with batteries are driven by the electrode materials. Based on the current diesel and electricity prices, there are also potential fuel cost savings associated with the use of EBs. At a diesel price of $\$ 3.90$ per gallon and an electricity price of 11 cents/kWh, transit agencies could save \$160,000 over 12 years of vehicle operation, which is not enough to recover the difference in capital cost since the EB is estimated to cost twice as much as a conventional diesel bus priced at $\$ 300,000$ (EIA, 2011a, 2011b). If the price of diesel drops below $\$ 2.80$ per gallon, the ICEB would be cheaper to run based on operation costs alone. With significant crude oil volatility over the last couple years, it may be difficult for transit agencies to justify EBs on the basis of operating cost savings alone.

The base case model utilized by this study had limitations and certain assumptions and simplifications were necessary to generate life cycle impact estimates. The EB for this study was a theoretical vehicle since specific details regarding EB prototypes are limited and proprietary. 
This study assumed that the impacts of the electric drivetrain were equal to that from the diesel engine drivetrain and that the ICEB and EB provided identical functionality. Without quick charging, it is unlikely that a single EB could replace and ICEB with identical functionality. The model also assumed that the EB and ICEB had identical lifetimes. Based proposed EB designs, a full evaluation of the components would be necessary to determine if electric drive technology could shorten or lengthen the lifetime of a transit bus.

Future studies could further develop the charging requirements for the EB and determine if quick charging is really feasible and if not, what type of service availability the EB would have versus the ICEB. While the use-phase impacts dominated most of the environmental impact categories, battery production was not insignificant. The emissions related to battery production were further compounded by the number of required battery replacements over the life of the EB. Future work could determine the optimum battery size and replacement schedule to minimize life cycle GHG emissions. It is also clear that there are other benefits of EBs that are substantial yet hard to quantify, for example noise pollution reduction and localized exposure to emissions. This study also did not address the difference in performance between the two technologies. Future work could further examine this area to determine if an EB would provide the same measure of functionality as an ICEB based on variables like terrain and weather. These effects should be considered to adequately assess both ICEB and EB technologies.

This study utilized both process LCA and EIO-LCA to model the environmental impacts of the EB and ICEB. There are clear advantages to both frameworks. Process LCA is much more detail oriented; however, this comes at the expense of data and time requirements. EIOLCA allows for a much quicker analysis; however, the tool does not allow the user to model specific systems and components, and rather provides an aggregate level estimation of the 
environmental impacts. A combination of these tools is beneficial because it allows the LCA practitioner to quickly model those processes that do not contribute significantly to the total life cycle impacts. Process LCA can then be used to hone in on specific elements of a process or product that are particularly important to overall environmental burdens. In this case, significant effort was focused on modeling the impacts of the Li-ion battery production and the EB and ICEB use phase impacts. Based on previous studies in the literature, it was clear that these two portions of the life cycle would be the most significant contributors to environmental impacts.

Another LCA issue that was confronted in this study was the choice of LCIA tool and the decision to provide midpoint instead of endpoint results for the different environmental impact categories. As illustrated by Figure 3-2, the use midpoint impacts provides decision maker with a higher level of certainty in the results than would a single endpoint metric; however, the choice as to which impacts are most important are still left up to the individual. Endpoint impacts would have provided a single metric; however, there is a higher level of uncertainty associated with these scores. Another issue with endpoint impacts is the issue of the weighting of different environmental impact categories, which clearly introduces subjectivity. Alternatively, this study could have provided only the LCI results for the analysis, which have a much higher level of certainty and are relatively objective; however, the usefulness of this data is much less from a policy perspective. 
APPENDIX A

\section{LCA MODEL INPUTS AND DATA SOURCES}

\begin{tabular}{|c|c|c|c|}
\hline $\begin{array}{c}\text { Common Operations } \\
\text { Inputs: }\end{array}$ & Value & Units & Source(s) \\
\hline Bus Operation Distance & 37009 & miles per year & $\begin{array}{l}\text { (Callaghan \& Lynch, 2005; } \\
\text { Chester \& Horvath, 2009b; } \\
\text { Laver, et al., 2007) }\end{array}$ \\
\hline Years of Operation & 12 & years & $\begin{array}{l}\text { (Callaghan \& Lynch, 2005; } \\
\text { Chester \& Horvath, 2009b; } \\
\text { Laver, et al., 2007) }\end{array}$ \\
\hline Total Operation Miles & 444108 & miles & Calculated \\
\hline Total Operation Kilometers & 714570 & $\mathrm{~km}$ & Calculated \\
\hline Daily Operation Miles & 101 & miles/day & Calculated \\
\hline \multicolumn{4}{|l|}{ ICEB Inputs: } \\
\hline Fuel Efficiency & 3.08 & mpg & $\begin{array}{l}\text { (American Public } \\
\text { Transportation Association, } \\
\text { 2010; Callaghan \& Lynch, } \\
\text { 2005; Clark, et al., 2007) }\end{array}$ \\
\hline Lifetime Diesel Fuel Use & 144191 & gallons & Calculated \\
\hline Lifetime Diesel Fuel Use & 545907 & liters & Calculated \\
\hline Daily operation fuel & 32.9 & gallons/day & Calculated \\
\hline Daily operation fuel & 124.6 & liters & Calculated \\
\hline Diesel Engine Efficiency & 0.45 & & $\begin{array}{l}\text { (DOE, 2000; ICF International, } \\
\text { 2009) }\end{array}$ \\
\hline Diesel Fuel Energy Content & 132000 & BTU/gal & $\begin{array}{l}\text { (DOE, 2000; ICF International, } \\
\text { 2009) }\end{array}$ \\
\hline \multicolumn{4}{|l|}{ EB Inputs: } \\
\hline Number of EBs per ICEB & 1 & buses & Assumption \\
\hline
\end{tabular}




\begin{tabular}{|c|c|c|c|}
\hline EB Inputs (cont'd): & & & \\
\hline Number of charging units & 1 & units & Assumption \\
\hline Electric drive efficiency & $75 \%$ & & $\begin{array}{l}\text { (Majeau-Bettez, et al., 2011; } \\
\text { Notter, et al., 2010; Samaras \& } \\
\text { Meisterling, 2008) }\end{array}$ \\
\hline Charger efficiency & $90 \%$ & & $\begin{array}{l}\text { (Bennion \& O'Keefe, 2010; } \\
\text { Bubna, et al., 2010; Callaghan } \\
\text { \& Lynch, 2005; Chester \& } \\
\text { Horvath, 2009b; Eudy \& } \\
\text { Gifford, 2003; Wayne \& } \\
\text { Sandoval, 2007) }\end{array}$ \\
\hline $\begin{array}{l}\text { Lifetime electricity grid } \\
\text { draw }\end{array}$ & 3718548 & $\mathrm{kWh}$ & Calculated \\
\hline $\begin{array}{l}\text { Lifetime equivalent } \\
\text { electricity }\end{array}$ & 3346693 & $\mathrm{kWh}$ & Calculated \\
\hline Daily operation electricity & 764 & kWh/day & Calculated \\
\hline Li-ion energy content & 112 & $\mathrm{Wh} / \mathrm{kg}$ & $\begin{array}{l}\text { (Bennion \& O'Keefe, 2010; } \\
\text { Majeau-Bettez, et al., 2011; } \\
\text { Notter, et al., 2010; Samaras \& } \\
\text { Meisterling, 2008) }\end{array}$ \\
\hline Required battery size & 6822 & $\mathrm{~kg}$ & Calculated \\
\hline Battery weight limit & 4000 & lbs & (Cummins Engines, 2010) \\
\hline Battery weight limit & 1814.1 & $\mathrm{~kg}$ & Calculated \\
\hline Installed battery size & 1814.1 & $\mathrm{~kg}$ & Calculated \\
\hline Daily charging stops & 3.8 & charges/day & Calculated \\
\hline Li-ion cycle life & 3000 & cycles & $\begin{array}{l}\text { (Bennion \& O'Keefe, 2010; } \\
\text { Majeau-Bettez, et al., 2011; } \\
\text { Notter, et al., 2010; Samaras \& } \\
\text { Meisterling, 2008) }\end{array}$ \\
\hline $\begin{array}{l}\text { Lifetime battery } \\
\text { replacements }\end{array}$ & 5.5 & batteries & Calculated \\
\hline
\end{tabular}




\section{APPENDIX B}

IMPACT 2002 LCIA RESULTS FOR VARIOUS PROCESSES AND FOR THE BASE

CASE COMPARISON OF THE ICEB AND EB

\begin{tabular}{|c|c|c|c|c|}
\hline & & Electricity & Diesel & Battery \\
\hline & Unit & $1 \mathrm{kWh}$ & 1 liter & $1 \mathrm{~kg}$ \\
\hline & LCI Source & USLCI & USLCI & EcoInvent \\
\hline Global warming & $\mathrm{kg} \mathrm{CO}_{2} \mathrm{eq}$ & 7.49E-01 & $3.35 \mathrm{E}+00$ & $1.71 \mathrm{E}+01$ \\
\hline Carcinogens & $\mathrm{kg} \mathrm{C}_{2} \mathrm{H}_{3} \mathrm{Cl}$ eq & 3.36E-04 & $1.08 \mathrm{E}-03$ & 3.13E-01 \\
\hline Non-carcinogens & $\mathrm{kg} \mathrm{C}_{2} \mathrm{H}_{3} \mathrm{Cl}$ eq & 8.01E-03 & $2.20 \mathrm{E}-01$ & $1.53 \mathrm{E}+00$ \\
\hline Respiratory inorganics & $\mathrm{kg} \mathrm{PM}_{2.5} \mathrm{eq}$ & 6.53E-04 & 3.37E-03 & 2.37E-02 \\
\hline Ozone layer depletion & kg CFC-11 eq & $6.62 \mathrm{E}-12$ & $1.29 \mathrm{E}-10$ & $2.19 E-04$ \\
\hline Respiratory organics & $\mathrm{kg} \mathrm{C}_{2} \mathrm{H}_{4} \mathrm{eq}$ & $4.38 \mathrm{E}-04$ & $1.70 \mathrm{E}-03$ & 4.86E-03 \\
\hline Aquatic ecotoxicity & kg TEG water & $5.09 \mathrm{E}+01$ & $1.46 \mathrm{E}+03$ & $1.30 \mathrm{E}+05$ \\
\hline Terrestrial ecotoxicity & kg TEG soil & 1.82E-01 & $1.62 \mathrm{E}-01$ & $4.15 \mathrm{E}+04$ \\
\hline Terrestrial acid/nutri & $\mathrm{kg} \mathrm{SO}_{2} \mathrm{eq}$ & 1.59E-02 & $1.35 \mathrm{E}-01$ & 3.80E-01 \\
\hline Aquatic acidification & $\mathrm{kg} \mathrm{SO}_{2} \mathrm{eq}$ & 6.72E-03 & 2.14E-02 & $1.80 \mathrm{E}-01$ \\
\hline Aquatic eutrophication & $\mathrm{kg} \mathrm{PO}_{4} \mathrm{P}$-lim & 1.53E-06 & $2.68 \mathrm{E}-05$ & 5.89E-04 \\
\hline
\end{tabular}




\begin{tabular}{|c|c|c|c|c|c|c|c|c|}
\hline \multicolumn{2}{|c|}{$\begin{array}{c}\text { Environmental Impact } \\
\text { per Vehicle km }\end{array}$} & \multirow{2}{*}{$\begin{array}{c}\text { Bus Type } \\
\text { ICEB }\end{array}$} & \multirow{2}{*}{$\begin{array}{c}\text { Shell } \\
2.78 \mathrm{E}-01 \\
\end{array}$} & \multirow{2}{*}{$\begin{array}{l}\text { Maint. } \\
2.25 \mathrm{E}-02 \\
\end{array}$} & \multirow{2}{*}{$\begin{array}{c}\text { Battery } \\
0.00 \mathrm{E}+00\end{array}$} & \multirow{2}{*}{$\begin{array}{c}\begin{array}{c}\text { Charging } \\
\text { Equip }\end{array} \\
0.00 \mathrm{E}+00 \\
\end{array}$} & \multirow{2}{*}{$\begin{array}{c}\begin{array}{c}\text { Use } \\
\text { Phase }\end{array} \\
2.56 \mathrm{E}+00\end{array}$} & \multirow{2}{*}{$\begin{array}{r}\text { Total } \\
2.86 \mathrm{E}+0 \mathrm{C} \\
\end{array}$} \\
\hline & & & & & & & & \\
\hline Warming & & EB & $2.78 \mathrm{E}-01$ & $1.69 \mathrm{E}-02$ & $2.81 \mathrm{E}-01$ & $4.87 \mathrm{E}-02$ & $3.90 \mathrm{E}+00$ & $4.52 \mathrm{E}+00$ \\
\hline \multirow{2}{*}{ Carcinogens } & \multirow{2}{*}{$\underset{\text { eq }}{\mathrm{Mg} \mathrm{\textrm {C } _ { 2 } \mathrm { H } _ { 3 } \mathrm { Cl }}}$} & ICEB & $3.29 \mathrm{E}-04$ & $2.18 \mathrm{E}-05$ & $0.00 \mathrm{E}+00$ & $0.00 \mathrm{E}+00$ & $8.27 \mathrm{E}-04$ & $1.18 \mathrm{E}-03$ \\
\hline & & EB & $3.29 \mathrm{E}-04$ & 1.63E-05 & $5.16 \mathrm{E}-03$ & $3.72 \mathrm{E}-04$ & $1.75 \mathrm{E}-03$ & 7.62E-03 \\
\hline \multirow{2}{*}{$\begin{array}{c}\text { Non- } \\
\text { carcinogens }\end{array}$} & \multirow{2}{*}{$\begin{array}{c}\mathrm{Mg} \mathrm{C}_{2} \mathrm{H}_{3} \mathrm{Cl} \\
\text { eq }\end{array}$} & ICEB & $3.44 \mathrm{E}-03$ & $2.28 \mathrm{E}-04$ & $0.00 \mathrm{E}+00$ & $0.00 \mathrm{E}+00$ & $1.68 \mathrm{E}-01$ & 1.72E-01 \\
\hline & & EB & $3.44 \mathrm{E}-03$ & $1.71 \mathrm{E}-04$ & $2.52 \mathrm{E}-02$ & $3.89 \mathrm{E}-03$ & 4.17E-02 & $7.44 \mathrm{E}-02$ \\
\hline \multirow{2}{*}{$\begin{array}{l}\text { Respiratory } \\
\text { inorganics }\end{array}$} & \multirow{2}{*}{ kg $\mathbf{P M}_{2.5}$ eq } & ICEB & 4.57E-07 & 2.79E-08 & $0.00 \mathrm{E}+00$ & $0.00 \mathrm{E}+00$ & $2.58 \mathrm{E}-03$ & $2.58 \mathrm{E}-03$ \\
\hline & & EB & $4.57 \mathrm{E}-07$ & 2.09E-08 & $3.90 \mathrm{E}-04$ & $1.11 \mathrm{E}-07$ & $3.40 \mathrm{E}-03$ & 3.79E-03 \\
\hline \multirow{2}{*}{$\begin{array}{c}\text { Ozone } \\
\text { Depletion }\end{array}$} & \multirow{2}{*}{$\begin{array}{c}\text { kg CFC-11 } \\
\text { eq }\end{array}$} & ICEB & $2.18 \mathrm{E}-07$ & 1.17E-08 & $0.00 \mathrm{E}+00$ & $0.00 \mathrm{E}+00$ & $9.83 \mathrm{E}-11$ & $2.29 \mathrm{E}-07$ \\
\hline & & EB & $2.18 \mathrm{E}-07$ & 8.75E-09 & 3.61E-06 & $4.10 \mathrm{E}-08$ & 3.44E-11 & 3.87E-06 \\
\hline \multirow{2}{*}{$\begin{array}{l}\text { Respiratory } \\
\text { organics }\end{array}$} & \multirow{2}{*}{$\mathrm{kg} \mathrm{C}_{2} \mathrm{H}_{4} \mathrm{eq}$} & ICEB & 3.58E-05 & $6.25 \mathrm{E}-07$ & $0.00 \mathrm{E}+00$ & $0.00 \mathrm{E}+00$ & $1.30 \mathrm{E}-03$ & 1.33E-03 \\
\hline & & EB & 3.58E-05 & 4.69E-07 & $8.01 \mathrm{E}-05$ & $1.67 \mathrm{E}-06$ & $2.28 \mathrm{E}-03$ & $2.40 \mathrm{E}-03$ \\
\hline \multirow{2}{*}{$\begin{array}{c}\text { Aquatic } \\
\text { ecotoxicity }\end{array}$} & \multirow{2}{*}{$\begin{array}{l}\text { Gg TEG } \\
\text { water }\end{array}$} & ICEB & $5.51 \mathrm{E}-04$ & $3.18 \mathrm{E}-05$ & $0.00 \mathrm{E}+00$ & $0.00 \mathrm{E}+00$ & $1.12 \mathrm{E}+03$ & $1.12 \mathrm{E}+03$ \\
\hline & & EB & 5.51E-04 & $2.38 \mathrm{E}-05$ & $2.14 \mathrm{E}+03$ & 3.37E-04 & $2.65 \mathrm{E}+02$ & $2.40 \mathrm{E}+03$ \\
\hline \multirow{2}{*}{$\begin{array}{l}\text { Terrestrial } \\
\text { ecotoxicity }\end{array}$} & \multirow{2}{*}{ Gg TEG soil } & ICEB & 4.74E-04 & $2.87 \mathrm{E}-05$ & $0.00 \mathrm{E}+00$ & $0.00 \mathrm{E}+00$ & $1.24 \mathrm{E}-01$ & $1.24 \mathrm{E}-01$ \\
\hline & & EB & 4.74E-04 & 2.15E-05 & $6.84 \mathrm{E}+02$ & $3.22 \mathrm{E}-04$ & $9.45 \mathrm{E}-01$ & $6.85 E+02$ \\
\hline \multirow{2}{*}{$\begin{array}{l}\text { Terrestrial } \\
\text { acid/nutri }\end{array}$} & \multirow{2}{*}{$\mathrm{kg} \mathrm{SO}_{2} \mathrm{eq}$} & ICEB & $5.64 \mathrm{E}-05$ & 3.43E-06 & $0.00 \mathrm{E}+00$ & $0.00 \mathrm{E}+00$ & 1.03E-01 & 1.03E-01 \\
\hline & & EB & $5.64 \mathrm{E}-05$ & $2.57 \mathrm{E}-06$ & $6.27 \mathrm{E}-03$ & $1.37 \mathrm{E}-05$ & $8.29 \mathrm{E}-02$ & 8.92E-02 \\
\hline \multirow{2}{*}{$\begin{array}{c}\text { Aquatic } \\
\text { acidification }\end{array}$} & \multirow{2}{*}{$\mathrm{kg} \mathrm{SO}_{2} \mathrm{eq}$} & ICEB & $3.25 \mathrm{E}-05$ & $2.47 \mathrm{E}-06$ & $0.00 \mathrm{E}+00$ & $0.00 \mathrm{E}+00$ & 1.63E-02 & $1.64 \mathrm{E}-02$ \\
\hline & & EB & 3.25E-05 & 1.85E-06 & $2.96 \mathrm{E}-03$ & 7.80E-06 & 3.50E-02 & 3.80E-02 \\
\hline \multirow{2}{*}{$\begin{array}{c}\text { Aquatic } \\
\text { eutrophication }\end{array}$} & \multirow{2}{*}{ kg $\mathrm{PO}_{4}$ P-lim } & ICEB & 7.76E-09 & 1.03E-09 & $0.00 \mathrm{E}+00$ & $0.00 \mathrm{E}+00$ & 2.05E-05 & 2.05E-05 \\
\hline & & EB & 7.76E-09 & $7.72 \mathrm{E}-10$ & $9.70 \mathrm{E}-06$ & $1.54 \mathrm{E}-09$ & 7.95E-06 & 1.77E-05 \\
\hline
\end{tabular}




\section{APPENDIX C}

\section{STATE-BY-STATE ELECTRICITY GENERATION AND CONSUMPTION MIXES}

FOR THE YEAR 2000 INCLUDING INTERSTATE TRADING PROJECTIONS

Based on the results from Marriott and Matthews (2005):

\begin{tabular}{|c|c|c|c|c|c|c|c|c|c|c|c|c|}
\hline \multirow[b]{2}{*}{ State } & \multicolumn{6}{|c|}{2000 Generation Mix } & \multicolumn{6}{|c|}{2000 Consumption Mix (Interstate trading included) } \\
\hline & Coal & Oil & Gas & Nuclear & Hydro & Other & Coal & Oil & Gas & Nuclear & Hydro & Other \\
\hline Alaska & $9 \%$ & $10 \%$ & $65 \%$ & $0 \%$ & $16 \%$ & $0 \%$ & $9 \%$ & $10 \%$ & $65 \%$ & $0 \%$ & $16 \%$ & $0 \%$ \\
\hline Alabama & $62 \%$ & $0 \%$ & $4 \%$ & $25 \%$ & $5 \%$ & $3 \%$ & $62 \%$ & $0 \%$ & $4 \%$ & $25 \%$ & $5 \%$ & $3 \%$ \\
\hline Arkansas & $55 \%$ & $1 \%$ & $9 \%$ & $26 \%$ & $5 \%$ & $4 \%$ & $56 \%$ & $1 \%$ & $9 \%$ & $26 \%$ & $5 \%$ & $4 \%$ \\
\hline Arizona & $46 \%$ & $0 \%$ & $10 \%$ & $34 \%$ & $10 \%$ & $0 \%$ & $46 \%$ & $0 \%$ & $10 \%$ & $34 \%$ & $10 \%$ & $0 \%$ \\
\hline California & $1 \%$ & $1 \%$ & $50 \%$ & $17 \%$ & $19 \%$ & $12 \%$ & $21 \%$ & $1 \%$ & $38 \%$ & $15 \%$ & $15 \%$ & $9 \%$ \\
\hline Colorado & $80 \%$ & $0 \%$ & $16 \%$ & $0 \%$ & $3 \%$ & $0 \%$ & $80 \%$ & $0 \%$ & $16 \%$ & $0 \%$ & $3 \%$ & $0 \%$ \\
\hline Connecticut & $9 \%$ & $21 \%$ & $12 \%$ & $49 \%$ & $2 \%$ & $6 \%$ & $9 \%$ & $21 \%$ & $12 \%$ & $49 \%$ & $2 \%$ & $6 \%$ \\
\hline Washington DC & $0 \%$ & $100 \%$ & $0 \%$ & $0 \%$ & $0 \%$ & $0 \%$ & $97 \%$ & $2 \%$ & $0 \%$ & $0 \%$ & $1 \%$ & $0 \%$ \\
\hline Delaware & $69 \%$ & $14 \%$ & $14 \%$ & $0 \%$ & $0 \%$ & $3 \%$ & $63 \%$ & $8 \%$ & $7 \%$ & $20 \%$ & $1 \%$ & $2 \%$ \\
\hline Florida & $39 \%$ & $18 \%$ & $22 \%$ & $17 \%$ & $0 \%$ & $4 \%$ & $42 \%$ & $16 \%$ & $20 \%$ & $18 \%$ & $1 \%$ & $4 \%$ \\
\hline Georgia & $64 \%$ & $1 \%$ & $4 \%$ & $26 \%$ & $2 \%$ & $3 \%$ & $65 \%$ & $1 \%$ & $4 \%$ & $26 \%$ & $2 \%$ & $3 \%$ \\
\hline Hawaii & $15 \%$ & $76 \%$ & $0 \%$ & $0 \%$ & $1 \%$ & $8 \%$ & $15 \%$ & $76 \%$ & $0 \%$ & $0 \%$ & $1 \%$ & $8 \%$ \\
\hline Iowa & $84 \%$ & $0 \%$ & $1 \%$ & $11 \%$ & $2 \%$ & $1 \%$ & $86 \%$ & $0 \%$ & $1 \%$ & $9 \%$ & $3 \%$ & $1 \%$ \\
\hline Idaho & $1 \%$ & $0 \%$ & $9 \%$ & $0 \%$ & $87 \%$ & $5 \%$ & $26 \%$ & $1 \%$ & $5 \%$ & $0 \%$ & $66 \%$ & $3 \%$ \\
\hline Illinois & $46 \%$ & $0 \%$ & $3 \%$ & $50 \%$ & $0 \%$ & $1 \%$ & $46 \%$ & $0 \%$ & $3 \%$ & $50 \%$ & $0 \%$ & $1 \%$ \\
\hline Indiana & $96 \%$ & $0 \%$ & $2 \%$ & $0 \%$ & $0 \%$ & $1 \%$ & $96 \%$ & $0 \%$ & $2 \%$ & $0 \%$ & $0 \%$ & $1 \%$ \\
\hline Kansas & $73 \%$ & $1 \%$ & $6 \%$ & $20 \%$ & $0 \%$ & $0 \%$ & $73 \%$ & $1 \%$ & $6 \%$ & $20 \%$ & $0 \%$ & $0 \%$ \\
\hline Kentucky & $97 \%$ & $0 \%$ & $1 \%$ & $0 \%$ & $3 \%$ & $0 \%$ & $97 \%$ & $0 \%$ & $1 \%$ & $0 \%$ & $3 \%$ & $0 \%$ \\
\hline Louisiana & $25 \%$ & $2 \%$ & $50 \%$ & $17 \%$ & $1 \%$ & $5 \%$ & $25 \%$ & $2 \%$ & $50 \%$ & $17 \%$ & $1 \%$ & $5 \%$ \\
\hline Massachusetts & $29 \%$ & $20 \%$ & $27 \%$ & $14 \%$ & $6 \%$ & $5 \%$ & $36 \%$ & $14 \%$ & $19 \%$ & $22 \%$ & $5 \%$ & $5 \%$ \\
\hline Maryland & $58 \%$ & $5 \%$ & $6 \%$ & $27 \%$ & $3 \%$ & $2 \%$ & $66 \%$ & $4 \%$ & $4 \%$ & $22 \%$ & $3 \%$ & $1 \%$ \\
\hline
\end{tabular}




\begin{tabular}{|c|c|c|c|c|c|c|c|c|c|c|c|c|}
\hline \multirow[b]{2}{*}{ State } & \multicolumn{6}{|c|}{2000 Generation Mix } & \multicolumn{6}{|c|}{2000 Consumption Mix (Interstate trading included) } \\
\hline & Coal & Oil & Gas & Nuclear & Hydro & Other & Coal & Oil & Gas & Nuclear & Hydro & Other \\
\hline Michigan & $65 \%$ & $1 \%$ & $12 \%$ & $18 \%$ & $0 \%$ & $3 \%$ & $61 \%$ & $1 \%$ & $12 \%$ & $18 \%$ & $7 \%$ & $3 \%$ \\
\hline Minnesota & $65 \%$ & $0 \%$ & $3 \%$ & $26 \%$ & $2 \%$ & $4 \%$ & $55 \%$ & $1 \%$ & $3 \%$ & $23 \%$ & $15 \%$ & $4 \%$ \\
\hline Missouri & $83 \%$ & $0 \%$ & $3 \%$ & $13 \%$ & $1 \%$ & $0 \%$ & $83 \%$ & $0 \%$ & $3 \%$ & $13 \%$ & $1 \%$ & $0 \%$ \\
\hline Mississippi & $37 \%$ & $8 \%$ & $22 \%$ & $28 \%$ & $0 \%$ & $5 \%$ & $41 \%$ & $6 \%$ & $18 \%$ & $31 \%$ & $0 \%$ & $4 \%$ \\
\hline Montana & $61 \%$ & $2 \%$ & $0 \%$ & $0 \%$ & $36 \%$ & $0 \%$ & $61 \%$ & $2 \%$ & $0 \%$ & $0 \%$ & $36 \%$ & $0 \%$ \\
\hline North Carolina & $62 \%$ & $1 \%$ & $1 \%$ & $32 \%$ & $3 \%$ & $2 \%$ & $62 \%$ & $1 \%$ & $1 \%$ & $32 \%$ & $3 \%$ & $2 \%$ \\
\hline North Dakota & $93 \%$ & $0 \%$ & $0 \%$ & $0 \%$ & $7 \%$ & $0 \%$ & $93 \%$ & $0 \%$ & $0 \%$ & $0 \%$ & $7 \%$ & $0 \%$ \\
\hline New Hampshire & $26 \%$ & $3 \%$ & $1 \%$ & $53 \%$ & $10 \%$ & $7 \%$ & $26 \%$ & $3 \%$ & $1 \%$ & $53 \%$ & $10 \%$ & $7 \%$ \\
\hline New Jersey & $17 \%$ & $2 \%$ & $28 \%$ & $50 \%$ & $0 \%$ & $3 \%$ & $27 \%$ & $2 \%$ & $22 \%$ & $47 \%$ & $0 \%$ & $3 \%$ \\
\hline New Mexico & $85 \%$ & $0 \%$ & $14 \%$ & $0 \%$ & $1 \%$ & $0 \%$ & $85 \%$ & $0 \%$ & $14 \%$ & $0 \%$ & $1 \%$ & $0 \%$ \\
\hline Nevada & $54 \%$ & $0 \%$ & $36 \%$ & $0 \%$ & $7 \%$ & $4 \%$ & $54 \%$ & $0 \%$ & $36 \%$ & $0 \%$ & $7 \%$ & $4 \%$ \\
\hline New York & $18 \%$ & $11 \%$ & $29 \%$ & $23 \%$ & $17 \%$ & $2 \%$ & $21 \%$ & $10 \%$ & $26 \%$ & $23 \%$ & $19 \%$ & $2 \%$ \\
\hline Ohio & $87 \%$ & $0 \%$ & $1 \%$ & $11 \%$ & $0 \%$ & $1 \%$ & $85 \%$ & $0 \%$ & $1 \%$ & $13 \%$ & $0 \%$ & $1 \%$ \\
\hline Oklahoma & $64 \%$ & $0 \%$ & $32 \%$ & $0 \%$ & $4 \%$ & $0 \%$ & $64 \%$ & $0 \%$ & $32 \%$ & $0 \%$ & $4 \%$ & $0 \%$ \\
\hline Oregon & $7 \%$ & $0 \%$ & $18 \%$ & $0 \%$ & $74 \%$ & $1 \%$ & $10 \%$ & $0 \%$ & $17 \%$ & $0 \%$ & $72 \%$ & $1 \%$ \\
\hline Pennsylvania & $57 \%$ & $2 \%$ & $1 \%$ & $37 \%$ & $1 \%$ & $2 \%$ & $57 \%$ & $2 \%$ & $1 \%$ & $37 \%$ & $1 \%$ & $2 \%$ \\
\hline South Carolina & $42 \%$ & $1 \%$ & $1 \%$ & $55 \%$ & $1 \%$ & $2 \%$ & $42 \%$ & $1 \%$ & $1 \%$ & $55 \%$ & $1 \%$ & $2 \%$ \\
\hline South Dakota & $35 \%$ & $1 \%$ & $3 \%$ & $0 \%$ & $62 \%$ & $0 \%$ & $35 \%$ & $1 \%$ & $3 \%$ & $0 \%$ & $62 \%$ & $0 \%$ \\
\hline Tennessee & $65 \%$ & $1 \%$ & $1 \%$ & $27 \%$ & $6 \%$ & $1 \%$ & $64 \%$ & $1 \%$ & $1 \%$ & $28 \%$ & $5 \%$ & $1 \%$ \\
\hline Texas & $37 \%$ & $1 \%$ & $50 \%$ & $10 \%$ & $0 \%$ & $2 \%$ & $37 \%$ & $1 \%$ & $50 \%$ & $10 \%$ & $0 \%$ & $2 \%$ \\
\hline Utah & $95 \%$ & $0 \%$ & $2 \%$ & $0 \%$ & $2 \%$ & $1 \%$ & $95 \%$ & $0 \%$ & $2 \%$ & $0 \%$ & $2 \%$ & $1 \%$ \\
\hline Virginia & $51 \%$ & $4 \%$ & $6 \%$ & $36 \%$ & $0 \%$ & $3 \%$ & $65 \%$ & $3 \%$ & $4 \%$ & $25 \%$ & $0 \%$ & $2 \%$ \\
\hline Vermont & $0 \%$ & $1 \%$ & $1 \%$ & $72 \%$ & $19 \%$ & $6 \%$ & $0 \%$ & $1 \%$ & $1 \%$ & $72 \%$ & $19 \%$ & $6 \%$ \\
\hline Washington & $9 \%$ & $1 \%$ & $7 \%$ & $8 \%$ & $75 \%$ & $2 \%$ & $9 \%$ & $1 \%$ & $7 \%$ & $8 \%$ & $75 \%$ & $2 \%$ \\
\hline Wisconsin & $71 \%$ & $1 \%$ & $4 \%$ & $19 \%$ & $3 \%$ & $2 \%$ & $62 \%$ & $1 \%$ & $4 \%$ & $18 \%$ & $14 \%$ & $2 \%$ \\
\hline West Virginia & $98 \%$ & $0 \%$ & $0 \%$ & $0 \%$ & $1 \%$ & $0 \%$ & $98 \%$ & $0 \%$ & $0 \%$ & $0 \%$ & $1 \%$ & $0 \%$ \\
\hline Wyoming & $96 \%$ & $0 \%$ & $1 \%$ & $0 \%$ & $2 \%$ & $1 \%$ & $96 \%$ & $0 \%$ & $1 \%$ & $0 \%$ & $2 \%$ & $1 \%$ \\
\hline
\end{tabular}




\section{APPENDIX D}

\section{STATE-BY-STATE COMPARISON OF LIFE CYCLE GLOBAL WARMING IMPACTS FOR THE EB AND ICEB}

Based on the interstate electricity trading model results from Marriott and Matthews (2005); electricity emissions factors calculated from USLCI (NREL, 2004), Hondo (2005), and Weisser (2007).

\begin{tabular}{|c|c|c|}
\hline & $\begin{array}{c}\text { Electricity Emission } \\
\text { Factor }\end{array}$ & Life Cycle \% Diff \\
\hline State & (kg C $\mathbf{~ O}_{\mathbf{k W h})}$ & EB vs. ICEB \\
\hline Alaska & 0.616 & $36 \%$ \\
\hline Alabama & 0.686 & $51 \%$ \\
\hline Arkansas & 0.652 & $43 \%$ \\
\hline Arizona & 0.555 & $24 \%$ \\
\hline California & 0.493 & $11 \%$ \\
\hline Colorado & 0.950 & $104 \%$ \\
\hline Connecticut & 0.374 & $-13 \%$ \\
\hline Washington DC & 1.032 & $121 \%$ \\
\hline Delaware & 0.778 & $69 \%$ \\
\hline Florida & 0.715 & $56 \%$ \\
\hline Georgia & 0.721 & $58 \%$ \\
\hline Hawaii & 0.856 & $85 \%$ \\
\hline Iowa & 0.908 & $96 \%$ \\
\hline Idaho & 0.321 & $-24 \%$ \\
\hline Illinois & 0.504 & $13 \%$ \\
\hline Indiana & 1.023 & $76 \%$ \\
\hline Kansas & 0.812 & \\
\hline & & \\
\hline
\end{tabular}




\begin{tabular}{|c|c|c|}
\hline & $\begin{array}{c}\text { Electricity Emission } \\
\text { Factor }\end{array}$ & Life Cycle \% Diff \\
\hline State & (kg CO$/$ /kWh) & EB vs. ICEB \\
\hline Kentucky & 1.019 & $118 \%$ \\
\hline Louisiana & 0.616 & $36 \%$ \\
\hline Massachusetts & 0.633 & $40 \%$ \\
\hline Maryland & 0.751 & $64 \%$ \\
\hline Maine & 0.390 & $-10 \%$ \\
\hline Michigan & 0.726 & $59 \%$ \\
\hline Minnesota & 0.604 & $34 \%$ \\
\hline Missouri & 0.892 & $92 \%$ \\
\hline Mississippi & 0.612 & $35 \%$ \\
\hline Montana & 0.667 & $47 \%$ \\
\hline North Carolina & 0.667 & $47 \%$ \\
\hline North Dakota & 0.975 & $109 \%$ \\
\hline Nebraska & 0.700 & $53 \%$ \\
\hline New Hampshire & 0.320 & $-24 \%$ \\
\hline New Jersey & 0.443 & $1 \%$ \\
\hline New Mexico & 0.987 & $112 \%$ \\
\hline Nevada & 0.800 & $74 \%$ \\
\hline New York & 0.485 & $10 \%$ \\
\hline Ohio & 0.902 & $94 \%$ \\
\hline Oklahoma & 0.879 & $90 \%$ \\
\hline Oregon & 0.229 & $-43 \%$ \\
\hline Pennsylvania & 0.631 & $39 \%$ \\
\hline Rhode Island & 0.644 & $42 \%$ \\
\hline South Carolina & 0.457 & $4 \%$ \\
\hline South Dakota & 0.399 & $-8 \%$ \\
\hline Tennessee & 0.687 & $51 \%$ \\
\hline Texas & 0.727 & $59 \%$ \\
\hline Utah & 1.011 & $116 \%$ \\
\hline Virginia & 0.740 & $61 \%$ \\
\hline Vermont & 0.031 & $-83 \%$ \\
\hline Washington & 0.156 & $-57 \%$ \\
\hline Wisconsin & 0.688 & $51 \%$ \\
\hline West Virginia & 1.034 & $121 \%$ \\
\hline Wyoming & 1.012 & $117 \%$ \\
\hline
\end{tabular}




\section{APPENDIX E}

\section{SENSITIVITY PARAMETER LCIA STUDY RESULTS FOR THE EB}

\begin{tabular}{|c|c|c|c|c|}
\hline \multicolumn{2}{|c|}{ Sensitivity Parameter } & \multicolumn{3}{|c|}{ Li-Ion Battery Energy Density (Wh/kg) } \\
\hline \multicolumn{2}{|c|}{ Environmental Impact per km } & Base (112) & 140 & \% Diff \\
\hline Global Warming & $\mathrm{kg} \mathrm{CO}{ }_{2}$ eq & $4.52 \mathrm{E}+00$ & $4.48 \mathrm{E}+00$ & $-1 \%$ \\
\hline Carcinogens & $\mathrm{kg} \mathrm{C}_{2} \mathrm{H}_{3} \mathrm{Cl}$ eq & 7.62E-03 & $6.75 \mathrm{E}-03$ & $-11 \%$ \\
\hline Non-carcinogens & $\mathrm{kg} \mathrm{C}_{2} \mathrm{H}_{3} \mathrm{Cl}$ eq & 7.44E-02 & 7.01E-02 & $-6 \%$ \\
\hline Respiratory inorganics & $\mathrm{kg} \mathrm{PM}_{2.5} \mathrm{eq}$ & 3.79E-03 & 3.72E-03 & $-2 \%$ \\
\hline Ozone Dep & kg CFC-11 eq & $3.87 \mathrm{E}-06$ & $3.26 \mathrm{E}-06$ & $-16 \%$ \\
\hline Respiratory organics & $\mathrm{kg} \mathrm{C}_{2} \mathrm{H}_{4} \mathrm{eq}$ & 2.40E-03 & 2.39E-03 & $-1 \%$ \\
\hline Aquatic ecotoxicity & kg TEG water & $2.40 \mathrm{E}+03$ & $2.04 \mathrm{E}+03$ & $-15 \%$ \\
\hline Terrestrial ecotoxicity & kg TEG soil & $6.85 \mathrm{E}+02$ & $5.69 \mathrm{E}+02$ & $-17 \%$ \\
\hline Terrestrial acid/nutri & $\mathrm{kg} \mathrm{SO}_{2}$ eq & 8.92E-02 & 8.82E-02 & $-1 \%$ \\
\hline Aquatic acidif & $\mathrm{kg} \mathrm{SO}_{2}$ eq & $3.80 \mathrm{E}-02$ & 3.75E-02 & $-1 \%$ \\
\hline Aquatic eutro & $\mathrm{kg} \mathrm{PO}_{4}$ P-lim & $1.77 \mathrm{E}-05$ & $1.60 \mathrm{E}-05$ & $-9 \%$ \\
\hline \multicolumn{2}{|c|}{ Sensitivity Parameter } & \multicolumn{3}{|c|}{ Li-Ion Battery Cycle Life (cycles) } \\
\hline \multicolumn{2}{|c|}{ Environmental Impact per km } & Base (3000) & 6000 & \% Diff \\
\hline Global Warming & $\mathrm{kg} \mathrm{CO}_{2}$ eq & $4.52 \mathrm{E}+00$ & $4.41 \mathrm{E}+00$ & $-3 \%$ \\
\hline Carcinogens & $\mathrm{kg} \mathrm{C}_{2} \mathrm{H}_{3} \mathrm{Cl}$ eq & 7.62E-03 & $5.44 \mathrm{E}-03$ & $-29 \%$ \\
\hline Non-carcinogens & $\mathrm{kg} \mathrm{C}_{2} \mathrm{H}_{3} \mathrm{Cl}$ eq & $7.44 \mathrm{E}-02$ & 6.37E-02 & $-14 \%$ \\
\hline Respiratory inorganics & $\mathrm{kg} \mathrm{PM}_{2.5} \mathrm{eq}$ & 3.79E-03 & 3.62E-03 & $-4 \%$ \\
\hline Ozone Dep & kg CFC-11 eq & 3.87E-06 & 2.35E-06 & $-39 \%$ \\
\hline Respiratory organics & $\mathrm{kg} \mathrm{C}_{2} \mathrm{H}_{4} \mathrm{eq}$ & 2.40E-03 & 2.37E-03 & $-1 \%$ \\
\hline Aquatic ecotoxicity & kg TEG water & $2.40 \mathrm{E}+03$ & $1.50 \mathrm{E}+03$ & $-38 \%$ \\
\hline Terrestrial ecotoxicity & kg TEG soil & $6.85 \mathrm{E}+02$ & $3.96 \mathrm{E}+02$ & $-42 \%$ \\
\hline Terrestrial acid/nutri & $\mathrm{kg} \mathrm{SO}_{2}$ eq & 8.92E-02 & 8.66E-02 & $-3 \%$ \\
\hline Aquatic acidif & $\mathrm{kg} \mathrm{SO}_{2}$ eq & $3.80 \mathrm{E}-02$ & 3.67E-02 & $-3 \%$ \\
\hline Aquatic eutro & $\mathrm{kg} \mathrm{PO}_{4} \mathrm{P}$-lim & $1.77 \mathrm{E}-05$ & $1.36 \mathrm{E}-05$ & $-23 \%$ \\
\hline
\end{tabular}




\begin{tabular}{|c|c|c|c|c|}
\hline \multicolumn{2}{|c|}{ Sensitivity Parameter } & \multicolumn{3}{|c|}{ Electric Drive Efficiency (\%) } \\
\hline \multicolumn{2}{|c|}{ Environmental Impact per km } & Base (75\%) & $85 \%$ & \% Diff \\
\hline Global Warming & $\mathrm{kg} \mathrm{CO}_{2}$ eq & $4.52 \mathrm{E}+00$ & $4.04 \mathrm{E}+00$ & $-11 \%$ \\
\hline Carcinogens & $\mathrm{kg} \mathrm{C}_{2} \mathrm{H}_{3} \mathrm{Cl}$ eq & 7.62E-03 & $6.90 \mathrm{E}-03$ & $-9 \%$ \\
\hline Non-carcinogens & $\mathrm{kg} \mathrm{C}_{2} \mathrm{H}_{3} \mathrm{Cl}$ eq & 7.44E-02 & $6.70 \mathrm{E}-02$ & $-10 \%$ \\
\hline Respiratory inorganics & $\mathrm{kg} \mathrm{PM}_{2.5} \mathrm{eq}$ & 3.79E-03 & 3.35E-03 & $-12 \%$ \\
\hline Ozone Dep & kg CFC-11 eq & 3.87E-06 & 3.52E-06 & $-9 \%$ \\
\hline Respiratory organics & $\mathrm{kg} \mathrm{C}_{2} \mathrm{H}_{4}$ eq & $2.40 \mathrm{E}-03$ & 2.12E-03 & $-12 \%$ \\
\hline Aquatic ecotoxicity & kg TEG water & $2.40 \mathrm{E}+03$ & $2.16 \mathrm{E}+03$ & $-10 \%$ \\
\hline Terrestrial ecotoxicity & kg TEG soil & $6.85 \mathrm{E}+02$ & $6.17 \mathrm{E}+02$ & $-10 \%$ \\
\hline Terrestrial acid/nutri & $\mathrm{kg} \mathrm{SO}_{2}$ eq & 8.92E-02 & 7.89E-02 & $-12 \%$ \\
\hline Aquatic acidif & $\mathrm{kg} \mathrm{SO}_{2} \mathrm{eq}$ & $3.80 \mathrm{E}-02$ & 3.36E-02 & $-12 \%$ \\
\hline Aquatic eutro & $\mathrm{kg} \mathrm{PO}_{4} \mathrm{P}$-lim & $1.77 \mathrm{E}-05$ & $1.58 \mathrm{E}-05$ & $-11 \%$ \\
\hline
\end{tabular}




\section{BIBLIOGRAPHY}

Ally, J., \& Pryor, T. (2007). Life-cycle assessment of diesel, natural gas and hydrogen fuel cell bus transportation systems. Journal of Power Sources, 170(2), 401-411. doi: DOI: 10.1016/j.jpowsour.2007.04.036

American Public Transportation Association. (2010). 2010 Public Transportation Fact Book (61 ed.). Washington, DC.

ANL. (2006). Development and Applications of GREET 2.7 - The Transportation Vehicle-Cycle Model. (ANL/ESD/06-5). Retrieved from http://www.transportation.anl.gov/pdfs/TA/378.PDF.

Armand, M., \& Tarascon, J. M. (2008). Building better batteries. [10.1038/451652a]. Nature, 451(7179), 652-657.

Bauman, H., \& Tillman, A.-M. (2004). The Hitch Hiker's Guide to LCA: Studentlitteratur AB.

Bennion, K., \& O'Keefe, M. (2010). Thermal Management of PHEV / EV Charging Systems. Retrieved from http://www1.eere.energy.gov/vehiclesandfuels/pdfs/merit_review_2010/power_electronic s/ape029_bennion_2010_p.pdf

Bubna, P., Brunner, D., Gangloff Jr, J. J., Advani, S. G., \& Prasad, A. K. (2010). Analysis, operation and maintenance of a fuel cell/battery series-hybrid bus for urban transit applications. Journal of Power Sources, 195(12), 3939-3949. doi: DOI: 10.1016/j.jpowsour.2009.12.080

Callaghan, L., \& Lynch, S. (2005). Analysis of Electric Drive Technologies For Transit Applications: Battery-Electric, Hybrid-Electric, and Fuel Cells. (FTA-MA-26-710005.1). Federal Transit Administration

Carnegie Mellon University Green Design Institute. (2008). Economic Input-Output Life Cycle Assessment (EIO-LCA). Retrieved from http://www.eiolca.net/index.html

Chester, M. V., \& Horvath, A. (2009a). Environmental assessment of passenger transportation should include infrastructure and supply chains. Environmental Research Letters, 4(2), 024008. 
Chester, M. V., \& Horvath, A. (2009b). Life-cycle Energy and Emissions Inventories for Motorcycles, Diesel Automobiles, School Buses, Electric Buses, Chicago Rail, and New York City Rail. UC Berkeley: UC Berkeley Center for Future Urban Transport: A Volvo Center of Excellence. Retrieved from http://escholarship.org/uc/item/6z37f2jr

Chester, M. V., Horvath, A., \& Madanat, S. (2010). Comparison of life-cycle energy and emissions footprints of passenger transportation in metropolitan regions. Atmospheric Environment, 44(8), 1071-1079. doi: DOI: 10.1016/j.atmosenv.2009.12.012

Clark, N. N., Zhen, F., Wayne, W. S., \& Lyons, D. W. (2007). Transit Bus Life Cycle Cost and Year 2007 Emissions Estimation. (FTA-WV-26-7004.2007.1). Federal Transit Administration

Cummins Engines. (2010). ISL EPA 2007 Urban Transit Bus Applications Spec Sheet Retrieved February 8, 2011, from http://cumminsengines.com/assets/pdf/4103683.pdf

Denholm, P., \& Short, W. (2006). An Evaluation of Utility System Impacts and Benefits of Optimally Dispatched Plug-In Hybrid Electric Vehicles. (NREL/TP-620-40293). Golden, CO: National Renewable Energy Laboratory.

DOE. (2000). Technology Roadmap for the 21st Century Truck Program. (21CT-001).

DOT. (2010). Number of U.S. Aircraft, Vehicles, Vessels, and Other Conveyances Retrieved June 23, 2011, from http://www.bts.gov/publications/national_transportation_statistics/html/table_01_11.html

EIA. (2009). Emissions of Greenhouse Gases in the United States 2008. (DOE/EIA-0573(2008)). Washington, DC: Retrieved from http://www.eia.doe.gov/oiaf/1605/ggrpt/pdf/0573\%282008\%29.pdf.

EIA. (2011a). Average Retail Price of Electricity to Ultimate Customers by End-Use Sector, by State Retrieved July 14, 2011, from http://www.eia.gov/cneaf/electricity/epm/table5_6_a.html

EIA. (2011b). Weekly Retail On-Highway Diesel Prices Retrieved July 14, 2011, from http://www.eia.gov/oog/info/wohdp/diesel_detail_report_combined.asp

EPA. (2009). National Nitrogen Oxides Emissions by Source Sector in 2005 Retrieved June 23, 2011, from http://www.epa.gov/air/emissions/nox.htm

Eudy, L., \& Gifford, M. (2003). Challenges and Experiences with Electric Propulsion Transit Buses in the United States. (DOE/GO-102003-1791). Oak Ridge, TN: U.S. Department of Energy. 
Gaines, L., \& Cuenca, R. (2000). Costs of lithium-ion batteries for vehicles. (ANL/ESD-42). Argonne National Laboratory Retrieved from http://www.osti.gov/energycitations/servlets/purl/761281-9hcCH0/webviewable/.

Hawkins, T., Hendrickson, C., Higgins, C., Matthews, H. S., \& Suh, S. (2006). A Mixed-Unit Input-Output Model for Environmental Life-Cycle Assessment and Material Flow Analysis. Environmental Science \& Technology, 41(3), 1024-1031. doi: 10.1021/es060871u

Hendrickson, C. T., Lave, L. B., \& Matthews, H. S. (2006). Environmental Life Cycle Assessment of Goods and Services An Input-Output Approach. Washington, DC: RFF Press.

Hischier, R., Weidema, B., Althaus, H.-J. r., Bauer, C., Doka, G., Dones, R., . . Nemecek, T. (2010). Implementation of Life Cycle Assessment Methods Final report ecoinvent v2.2 No. 3. Dübendorf, CH: Swiss Centre for Life Cycle Inventories.

Hondo, H. (2005). Life cycle GHG emission analysis of power generation systems: Japanese case. Energy, 30(11-12), 2042-2056. doi: DOI: 10.1016/j.energy.2004.07.020

ICF International. (2009). Comparative Evaluation of Rail and Truck Fuel Efficiency on Competitive Corridors. (DTFR53-07-Q-00021). Federal Railroad Administration.

ISO. (2006). Environmental management - Life cycle assessment - Requirements and guidelines. Switzerland: International Organization for Standardization.

Jaramillo, P., Griffin, W. M., \& Matthews, H. S. (2007). Comparative Life-Cycle Air Emissions of Coal, Domestic Natural Gas, LNG, and SNG for Electricity Generation. Environmental Science \& Technology, 41(17), 6290-6296. doi: 10.1021/es063031o

Jolliet, O., Margni, M., Charles, R., Humbert, S., Payet, J., Rebitzer, G., \& Rosenbaum, R. (2003). IMPACT 2002+: A new life cycle impact assessment methodology. The International Journal of Life Cycle Assessment, 8(6), 324-330. doi: 10.1007/bf02978505

Koren, H. S. (1995). Associations between Criteria Air Pollutants and Asthma. Environmental Health Perspectives, 103, 235-242.

Laver, R., Schneck, D., Skorupski, D., Brady, S., \& Cham, L. (2007). Useful Life of Transit Buses and Vans. (FTA VA-26-7229-07.1). Federal Transit Administration.

Majeau-Bettez, G., Hawkins, T. R., \& Stromman, A. H. (2011). Life Cycle Environmental Assessment of Lithium-Ion and Nickel Metal Hydride Batteries for Plug-in Hybrid and Battery Electric Vehicles. Environmental Science \& Technology, 45(10), 4548-4554. doi: 10.1021/es103607c 
Marriott, J., \& Matthews, H. S. (2005). Environmental Effects of Interstate Power Trading on Electricity Consumption Mixes. Environmental Science \& Technology, 39(22), 85848590. doi: 10.1021/es0506859

Matheys, J., Van Autenboer, W., Timmermans, J.-M., Van Mierlo, J., Van den Bossche, P., \& Maggetto, G. (2007). Influence of functional unit on the life cycle assessment of traction batteries. The International Journal of Life Cycle Assessment, 12(3), 191-196. doi: 10.1065/lca2007.04.322

McCleese, D., \& LaPuma, P. (2002). Using monte carlo simulation in life cycle assessment for electric and internal combustion vehicles. The International Journal of Life Cycle Assessment, 7(4), 230-236. doi: 10.1007/bf02978878

Notter, D. A., Gauch, M., Widmer, R., Wäger, P., Stamp, A., Zah, R., \& Althaus, H.-J. r. (2010). Contribution of Li-Ion Batteries to the Environmental Impact of Electric Vehicles. Environmental Science \& Technology, 44(17), 6550-6556. doi: 10.1021/es903729a

NREL. (2004). U.S. LCI Database Project - User's Guide. (NREL/BK-35854).

Ou, X., Zhang, X., \& Chang, S. (2010). Alternative fuel buses currently in use in China: Lifecycle fossil energy use, GHG emissions and policy recommendations. Energy Policy, 38(1), 406-418. doi: DOI: 10.1016/j.enpol.2009.09.031

PAAC. (2010). Port Authority Statistics Retrieved September 30, 2010, from http://www.portauthority.org/PAAC/CompanyInfo/GeneralStatistics/tabid/68/Default.asp $\underline{x}$

PENNDOT. (2007). Pennsylvania Urban Transit Statistical Report Fiscal Year 2005-2006. Retrieved from ftp://ftp.dot.state.pa.us/public/Bureaus/PublicTransportation/Urban/PAUrbanTransitStatis ticalReport2005-2006.pdf.

Rydh, C. J., \& Sandén, B. A. (2005). Energy analysis of batteries in photovoltaic systems. Part I: Performance and energy requirements. Energy Conversion and Management, 46(11-12), 1957-1979. doi: DOI: 10.1016/j.enconman.2004.10.003

Samaras, C., \& Meisterling, K. (2008). Life Cycle Assessment of Greenhouse Gas Emissions from Plug-in Hybrid Vehicles: Implications for Policy. Environmental Science \& Technology, 42(9), 3170-3176. doi: 10.1021/es702178s

Shiau, C.-S. N., Samaras, C., Hauffe, R., \& Michalek, J. J. (2009). Impact of battery weight and charging patterns on the economic and environmental benefits of plug-in hybrid vehicles. Energy Policy, 37(7), 2653-2663. doi: DOI: 10.1016/j.enpol.2009.02.040 
Silva, C., Ross, M., \& Farias, T. (2009). Evaluation of energy consumption, emissions and cost of plug-in hybrid vehicles. Energy Conversion and Management, 50(7), 1635-1643. doi: DOI: 10.1016/j.enconman.2009.03.036

Suh, S., Lenzen, M., Treloar, G. J., Hondo, H., Horvath, A., Huppes, G., . . Norris, G. (2003). System Boundary Selection in Life-Cycle Inventories Using Hybrid Approaches. Environmental Science \& Technology, 38(3), 657-664. doi: 10.1021/es0263745

Tzeng, G.-H., Lin, C.-W., \& Opricovic, S. (2005). Multi-criteria analysis of alternative-fuel buses for public transportation. Energy Policy, 33(11), 1373-1383. doi: DOI: 10.1016/j.enpol.2003.12.014

UNEP. (2005). Life Cycle Approaches - The road from analysis to practice, from http://www.unep.fr/scp/publications/details.asp?id=DTI/0594/PA

Clean Air Act, United States § 42 USC 85 (1990).

Wayne, W. S., \& Sandoval, J. A. (2007). Environmental Benefits of Alternative Fuels and Advanced Technology in Transit. (FTA-WV-26-7003-07.2). Federal Transit Administration.

Weisser, D. (2007). A guide to life-cycle greenhouse gas (GHG) emissions from electric supply technologies. Energy, 32(9), 1543-1559. doi: DOI: 10.1016/j.energy.2007.01.008

Wirasingha, S. G., Schofield, N., \& Emadi, A. (2008). Feasibility analysis of converting a Chicago Transit Authority (CTA) transit bus to a plug-in hybrid electric vehicle. Paper presented at the 2008 IEEE Vehicle Power and Propulsion Conference, VPPC 2008, September 3, 2008 - September 5, 2008, Harbin, China. 